\title{
O Modelo do sistema energético de hidrogênio solar e o Estado do Ceará
}

\author{
The Model of Solar Hydrogen Energy System and the State of Ceara
}

\section{Rodrigo Alves Patrício rodrigo.alpa@hotmail.com}

Natasha Esteves Batista estevesnatasha@hotmail. com

Thiago do Carmo Sousa thiagodocarmo92@gmail. com

Antonia Débora Sales

deborauece@yahoo.com.br

Elissandro Monteiro do

Sacramento

elimonsac@hotmail.com

Lutero Carmo de Lima

lutero.lima@uece.br

Universidade Estadual do Ceará

T. Nejat Veziroglu

veziroglu@iahe.org

\begin{abstract}
Resumo
O modelo computacional do sistema energético à base de hidrogênio advindo da energia solar é estudado neste artigo. Desde a sua criação, em 1975, o modelo computacional foi aplicado para diversos países do mundo, inclusive o Brasil. Em 2007, o modelo foi adaptado para o estado do Ceará, devido ao seu altíssimo potencial de energias renováveis, principalmente as energias solar e eólica. O modelo considera inter-relações de parâmetros, tais como população, demanda energética e Produto Interno Bruto per capita da região onde é aplicado; além disso, faz estimativas em longo prazo da produção de hidrogênio via energia solar. Preço da energia, área necessária para os painéis fotovoltaicos, capacidade da usina de dessalinização, investimentos de capital, custo de operação e manutenção, impactos socioeconômicos e ambientais também são incluídos no modelo, que sofreu adaptações para o estado do Ceará, incluindo a energia eólica e gás natural. O objetivo é o desenvolvimento sustentável desse importante estado da federação brasileira.
\end{abstract}

Palavras-chave: Economia do hidrogênio. Modelo computacional. Energia Renovável. Energia solar.

\begin{abstract}
The computational model of the Solar Hydrogen Energy System was studied in this article. Since its creation in 1975, the computational model was applied to various countries around the World, including Brazil. At year 2007, it was applied to the Ceará State considering the high potential in renewable energies of such State mainly solar and wind energies. The model considers interrelationships of parameters such as population, energy demand, gross internal product per capita of the region where it is applied and makes long term estimates of the production of solar hydrogen. Price of energy, necessary area of photovoltaic panels, capacity of desalination plant, capital investments, cost of operation and maintenance and socio-economical and environmental impacts were also included in such model. The model received adaptations for the Ceará State, including the wind energy and natural gas. The objective is the sustainable development of this important federative State of Brazil.
\end{abstract}

Keywords: Hydrogen economy. Computational model. Renewable energy. Solar energy.

\section{Introdução}

A utilização cada vez maior dos combustíveis fósseis pela humanidade tem acarretado crises ambientais, as quais, eventualmente, poderão colocar em risco a vida no planeta Terra. As energias renováveis, tais como a energia solar, eólica, hidráulica etc., apresentam-se como mitigadoras dos efeitos nefastos causados pela utilização dos combustíveis fósseis. Entretanto, apesar de as energias renováveis serem ambientalmente benéficas, elas apresentam natureza intermitente, causando o sério problema que é a disponibilidade da energia elétrica na hora de maior demanda. Surge daí a necessidade de se armazenar a energia de origem renovável quando disponível e empregá-la quando há aumento da demanda. A bateria elétrica serve como armazenador, entretanto, é dispendiosa, pesada e não suporta grandes pacotes de energia elétrica acumulada. Uma solução para esse problema tem sido a utilização do hidrogênio eletrolítico como armazenador de energia. 
O hidrogênio, que não é um combustível primário, é encontrado quase sempre associado a outros elementos químicos, e para utilizá-lo é necessário extraí-lo de sua fonte de origem, o que normalmente implica no gasto de certa quantidade de energia química, térmica e/ou elétrica.

Apesar de a energia cedida pelo hidrogênio ser menor do que a energia total utilizada na sua aquisição, ela apresenta vantagens importantes que a qualificam como um dos combustíveis que certamente irá substituir os combustíveis derivados do petróleo. A principal vantagem do hidrogênio é que reações químicas necessárias para reconvertê-lo em energia útil produzem somente água como produto final, ou seja, não há emissão de gases poluentes ou gases de efeito estufa. Outras vantagens são seu alto poder calorífico, apesar da pequena massa específica, não ser tóxico e ser bastante reativo (CGEE, 2004).

O presente trabalho detalha um estudo sobre o modelo computacional do sistema energético de hidrogênio solar, que elabora projeções sobre aspectos técnicos, sociais e econômicos a respeito do uso ou não da economia do hidrogênio no mundo, no Brasil e, mais recentemente, no estado do Ceará.

\section{Revisão do Estado da Arte}

\subsection{0 hidrogênio como vetor energético}

O hidrogênio tem muitas aplicações no campo de geração de energia. Pode ser usado em substituição aos combustíveis fósseis nos motores de combustão interna. Ele também é utilizado para produzir calor, refrigeração e reconversão para a geração de energia elétrica (SOUZA, 1994). Os motores de combustão interna a hidrogênio são em torno de $20 \%$ mais eficientes do que seus correspondentes à base de combustíveis fósseis. Isso se deve às elevadas taxa de compressão e maior calor específico do hidrogênio em relação aos combustíveis tradicionais. A maior vantagem da utilização do hidrogênio nos motores de combustão interna é o produto da combustão: vapor de água e baixa emissão de $\mathrm{NO}_{\mathrm{x}}$ (BARBIR, 1999).

Como a energia elétrica, o hidrogênio precisa ser obtido de alguma fonte de energia primária. Atualmente, é através da reforma do gás natural ou do petróleo em alta temperatura. Pode-se observar na Figura 1.1 o porcentual da produção de hidrogênio e suas respectivas formas de obtenção. Refinarias usam o gás para purificar combustíveis derivados do petróleo, e a indústria química o emprega para produzir amônia e outros compostos.

Fig. 1.1 - Principais fontes de produção de hidrogênio. Fonte: HIS, 2004
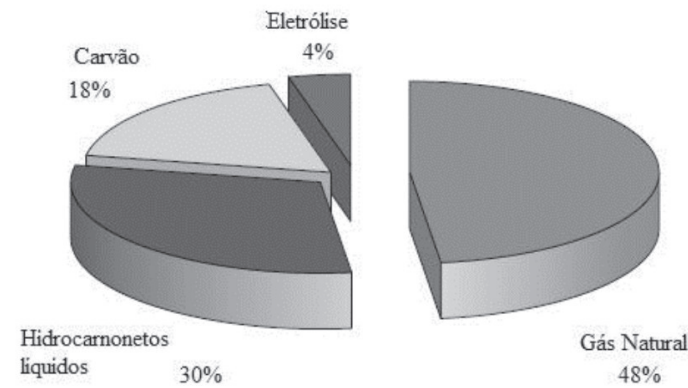

Entretanto, derivar hidrogênio de combustíveis fósseis gera $\mathrm{CO}_{2}$ como subproduto. Sua produção a partir do gás natural e utilização em um veículo a hidrogênio eficiente resultaria numa emissão total de gases do efeito estufa da ordem de 110 gramas por quilômetro dirigido. Essa quantidade é um pouco menor do que a liberada pelos veículos híbridos à gasolina/eletricidade $(150 \mathrm{~g} / \mathrm{km})$ e significativamente inferior à dos carros convencionais à gasolina, os quais giram em torno de $195 \mathrm{~g} / \mathrm{km}$ (Ogden, 2006).

A meta ideal é produzir hidrogênio com pouca ou nenhuma liberação de gases de efeito estufa. Uma forma que torna isso possível é a eletrólise da água pela energia gerada por fontes renováveis, como turbinas eólicas ou células solares.

O hidrogênio produzido a partir da energia gerada pelos aerogeradores ou painéis fotovoltaicos é denominado "limpo", mas os custos para a implantação de sistemas híbridos envolvendo essas fontes alternativas de energia são ainda elevados. Porém, há a necessidade de redução de poluentes na atmosfera, devido, principalmente, à queima de 
combustíveis fósseis. Dessa forma, justificam-se investimentos no desenvolvimento de novas tecnologias alternativas, como a fotovoltaica e a eólica (SACRAMENTO, 2007).

\subsection{Evolução histórica do modelo matemático para a geração do hidrogênio energético solar}

Em meados da década de 1970, VEZIROGLU e BASAR (1975), na Universidade de Miami, apresentaram pela primeira vez o modelo matemático para predizer as implicações técnicas, socioeconômicas e ambientais relativas à introdução universal do hidrogênio como um combustível alternativo para os combustíveis fósseis. A proposta do modelo consistia, essencialmente, na produção de hidrogênio através da eletrólise da água usando-se a energia solar. Esse modelo matemático precursor foi aprimorado, recebeu uma nova nomenclatura - "Solar Hydrogen Energy System" - e foi aplicado em diversos países e regiões do mundo, como Paquistão, Líbia, Egito, Emirados Árabes Unidos, Arábia Saudita, Espanha e Brasil, especialmente no estado do Ceará.

O modelo aprimorado prevê a produção de hidrogênio através da eletrólise da água, com os subprodutos (hidrogênio e oxigênio) sendo separados e armazenados. O oxigênio é um subproduto que também gera lucros, podendo ser aproveitado pelas indústrias. Para que se realize a eletrólise da água, a eletricidade seria produzida nos painéis fotovoltaicos. Quanto maior a eficiência de conversão (transformação da energia solar em energia elétrica), menores serão os custos para a produção de eletricidade e hidrogênio.

A produção de hidrogênio utilizando a água como matéria-prima para a eletrólise é um processo simples e, no sentido tecnológico, plenamente dominado. A água para a eletrólise, se vier do mar, deve ser dessalinizada através das usinas de dessalinização e abastecidas por energia elétrica proveniente também dos painéis fotovoltaicos. A água do mar, além de ser dessalinizada para a eletrólise, também poderia ser utilizada para a irrigação da área entre os painéis fotovoltaicos utilizados para a agricultura.

Após sua produção, o hidrogênio poderá ser estocado como um gás pressurizado em reservatórios próprios e, em seguida, distribuído para o consumo por meio de gasodutos ou transportadora, na forma líquida, por containeres.

Desde a primeira publicação até a chegada desse modelo matemático ao Brasil, não houve alterações no que se refere às equações fundamentais. Obviamente, o que deve ser alterado para cada caso são as variáveis iniciais de cada equação. Os parâmetros incluídos no modelo são: população, demanda de energia, produto nacional bruto, taxas de introdução de hidrogênio, importação de energia fóssil, preços mundiais de energia, poluição do ar, qualidade de vida, economia ambiental devido à maior eficiência de utilização de hidrogênio, ganho de subproduto, ganho agrícola, ganho na venda de hidrogênio, área de célula fotovoltaica, área total do terreno, capacidade da usina de dessalinização da água, capital de investimento, custo de operação e manutenção e renda total do sistema. No Brasil, o modelo experimentou modificações devido à introdução de novas equações e parâmetros.

Um dos primeiros trabalhos divulgados foi de autoria de ELJRUSHI e VEZIROGLU (1990), no qual o modelo do sistema energético de hidrogênio solar foi aplicado na Líbia visando à obtenção de relações entre a energia fóssil consumida nesse país e as variações dos parâmetros socioeconômicos e ambientais resultantes da utilização desse tipo de combustível contra a sua substituição pelo hidrogênio energético de origem solar fotovoltaica. A magnitude e a tendência dos parâmetros, com e sem a introdução de hidrogênio, foram investigadas por um determinado período de tempo. Os resultados indicaram que os recursos de combustíveis fósseis da Líbia poderiam se esgotar num prazo de três a quatro décadas. Eles também indicaram que, se houvesse a adoção do sistema energético de hidrogênio solar, poderse-ia estender a disponibilidade dos recursos de combustíveis fósseis, reduzir as emissões de poluentes atmosféricos e estabelecer um sistema permanente de energia para a Líbia. Enfim, a Líbia poderia se tornar um exportador de hidrogênio, em vez de petróleo e gás natural.

Outro artigo (“A clean and permanent energy infrastructure for Pakistan: solar-hydrogen energy system”), também de grande importância e muito referenciado, foi elaborado por LUTFI e VEZIROGLU (1990). Estes propuseram a introdução do sistema de hidrogênio solar no Paquistão como o melhor substituto para os combustíveis fósseis. O hidrogênio seria produzido através do processo eletrolítico e alimentado com energia solar fotovoltaica, utilizando terrenos ensolarados e disponíveis que não fossem usados pela agricultura na região desértica do Baluquistão. Foi idealizada também uma usina de dessalinização para usar a água do mar.

A partir do estudo direcionado para a Espanha, elaborado por CONTRERAS et al. (1999), concluiu-se que, se não for introduzido o sistema de hidrogênio solar, o país continuará a importar grandes quantidades de combustíveis fósseis durante este século, prejudicando o meio ambiente. Por outro lado, se forem usadas terras improdutivas que se 
localizam nas regiões central e sul da Espanha para a produção de hidrogênio via eletrólise, com o auxilio da energia solar, o país reduziria sua dependência de energia advinda de outros países. Com isso, a Espanha poderia até se tornar uma exportadora de energia e criaria um ambiente favorável para o crescimento do PIB, aumento da qualidade de vida e desenvolvimento sustentável.

ABDALLAH et al. (1999) aplicaram o modelo no Egito. Como a maioria dos países no mundo depende de combustíveis fósseis, o Egito, que é limitado nos recursos dessa natureza, certamente irá enfrentar situações de déficit de energia em médio e longo prazo. Os autores citaram que a energia solar é o recurso energético natural mais abundante daquele país e seria indispensável para o Egito a exploração dessa importante fonte de energia. Ele poderia utilizá-la para a produção de hidrogênio e, em seguida, utilizando o hidrogênio como vetor energético, exportá-lo para a Europa. Isso daria ao Egito um sistema de energia limpo e permanente, o que permitiria aumentar seu PIB, bem como melhorar a qualidade de vida da sua população.

Foi realizada uma análise preliminar sobre a possibilidade técnica e econômica de se executar um sistema de energia solar-hidrogênio para os Emirados Árabes Unidos (EAU), a fim de manter a sua cota de energia no mercado mundial futuramente (KAZIM e VEZIROGLU, 2000). O estudo previu que parte da demanda do mercado de petróleo dos EAU não seria suficiente para satisfazer as suas necessidades energéticas até 2015, enquanto no caso do gás natural seria até o ano de 2042. Isso resultaria em consequências graves para esse país no que se refere à economia. Nesse trabalho, os autores recomendaram que os EAU unissem forças políticas com outros países do Golfo Pérsico, tais como Arábia Saudita, Omã e Qatar, para a construção de um ou mais gasodutos para transporte de gás natural e hidrogênio. Na fase inicial, tanto o gás natural quanto o hidrogênio poderiam ser transportados para a Europa; posteriormente, quando as reservas de gás natural estivessem quase esgotadas, transportaria-se somente o hidrogênio. A renda gerada na venda do hidrogênio seria mínima no início, mas depois aumentaria para $90 \%$ do total da renda gerada pela venda de energia produzida no país na virada do século, conforme salientaram os autores.

Já ALMOGREN e VEZIROGLU (2004) produziram um artigo que tinha como objetivo estudar a aplicação desse modelo na Arábia Saudita e apontaram que as receitas desse país vêm essencialmente da exportação dos combustíveis fósseis. Tendo em vista que as reservas desses combustíveis são limitadas, o que levará ao seu esgotamento em um futuro não muito longínquo, a exploração da energia solar para a produção de hidrogênio seria uma interessante opção energética. Seguindo a mesma linha dos estudos anteriores, os pesquisadores concluíram que o hidrogênio poderia ser produzido e, em seguida, utilizado como vetor energético, sendo capaz até de exportá-lo para outros países, proporcionando um sistema energético limpo e permanente.

O primeiro trabalho que emprega tal metodologia no Brasil foi realizado por DE LIMA (1991), precisamente para o nordeste brasileiro. Na época, o pesquisador considerava que o nordeste do Brasil era, e continua sendo, uma região com um nível de insolação relativamente elevado e com pouca disponibilidade de água para fins agrícolas, industriais e residenciais. Foi observado que a economia do hidrogênio solar não era totalmente possível para o Brasil daquela época, mas, com o aumento dos problemas devido à utilização dos combustíveis fósseis, como o seu esgotamento, poluição e preço, foi previsto que em duas a três décadas a energia solar fotovoltaica teria uma tecnologia mais madura e preços competitivos, criando condições para que o sistema de hidrogênio solar passasse a ser uma realidade para o nordeste brasileiro.

SOUZA (1994) aplicou o modelo do hidrogênio solar para o Brasil como um todo, analisando aspectos técnicos, sociais e ambientais. Ele concluiu que o Brasil, como um país em desenvolvimento, necessita cada vez mais de energia para seu crescimento e para a melhoria da qualidade de vida de sua população. Presumiu que, devido ao aprimoramento tecnológico, ocorreria uma diminuição dos custos das células fotovoltaicas no decorrer dos anos, e com isso haveria a possibilidade de introduzir um combustível alternativo e renovável à base de hidrogênio solar, cujo uso como energético leva a um acréscimo na qualidade de vida da população, à diminuição das taxas de poluição atmosférica e a uma maior arrecadação devido à exportação do hidrogênio.

Após haver um trabalho com tal modelo matemático voltado para o Brasil, e outro trabalho voltado para uma região do país, mais precisamente a região nordeste do Brasil, SACRAMENTO (2007, 2008a, 2008b) centralizou ainda mais a região estudada e desenvolveu sua dissertação de mestrado tomando como região de estudo o estado do Ceará. Ele fez em seu trabalho um levantamento do balanço energético, bem como o potencial eólico e solar do Ceará; com isso, também fez um estudo detalhado da participação e contribuição de cada insumo energético na matriz energética do estado. SACRAMENTO inovou com seu trabalho, executando modificações no modelo matemático e aproveitando que o 
Ceará reúne ótimas condições tanto para a energia solar quanto para a energia eólica. No modelo adaptado para o estado, a energia eólica é prevista para executar as tarefas de bombeamento da água do mar, dessalinizar e realizar a eletrólise.

SALES (2010) também fez sua dissertação tomando como região de estudo o estado do Ceará e realizou a segunda grande modificação no corpo do modelo matemático, substituindo totalmente a energia fotovoltaica usada nas publicações anteriores para energia eólica com a função explícita de bombeamento, dessalinização e eletrólise da água do mar. Outra modificação executada por SALES foi o estudo da eventual substituição do gás natural pelo hidrogênio (enquanto os trabalhos anteriores analisaram a substituição dos combustíveis fósseis mais poluidores, como óleo diesel, gasolina, óleo combustível e gás liquefeito de petróleo - GLP), visto que as mudanças seriam brandas, pois, da forma como o gás natural é transportado (em caminhões e navios-tanque ou gasodutos), o hidrogênio, tanto na forma gasosa quanto na líquida, seria transportado na mesma rede do gás natural, carecendo de poucas mudanças e adaptações.

Na seção seguinte, o modelo matemático para a geração de hidrogênio energético de origem solar é apresentado e comentários sobre suas equações constitucionais são feitos. Observa-se que é um modelo simples e de fácil implementação, preciso em suas previsões e amigável quando introduzidos novos parâmetros e variáveis, conforme será verificado em outro artigo, complementar a este.

\section{Modelo de Hidrogênio Solar}

A seguir, nas subseções seguintes, serão apresentados os parâmetros que estão incluídos no modelo original usado pela maioria dos trabalhos publicados na literatura mundial. Os parâmetros são: população do local de estudo, demanda energética, Produto Nacional Bruto (PNB) ou Produto Interno Bruto (PIB), taxa de introdução de hidrogênio, importação de energia fóssil, preços do hidrogênio, poluição atmosférica, índice de qualidade de vida, economia ambiental devido à maior eficiência de utilização do hidrogênio, ganho agrícola, ganho na venda do hidrogênio, ganho na venda de oxigênio gerado, volume de água demandada pela usina de dessalinização, capital total demandado para o investimento, custos de operação e manutenção e renda total do sistema proposto.

\subsection{População}

Conhecendo um valor inicial da população e sua taxa de crescimento, pode-se estimar a população em um tempo futuro pela seguinte relação:

$Q_{n}=Q_{n-1} \exp \left[(\ln 2)\left(\Delta \mathrm{t}_{\mathrm{n}}\right)\left(\mathrm{W}_{\mathrm{n}}\right) \times \frac{1}{\theta_{q 0}}\right]$
em que

$Q_{n}=$ População no ano $n$;

$Q_{n-1}=$ População no ano anterior $n-1$;

$\Delta t=t_{n}-t_{n-1}$

$W_{n}=$ Modificador de crescimento populacional no intervalo de tempo $\Delta \mathrm{t}$;

$\theta_{q 0}=$ Tempo de dobramento inicial para a população local.

O valor de $\theta_{q 0}$ para o local de estudo pode ser obtido através de cálculos estatísticos, considerando-se a taxa média geométrica de crescimento anual da população. Já o valor de $\theta_{q 0}$ para o mundo pode ser obtido pela análise estatística da evolução do crescimento populacional durante os vinte anos antecedentes ao ano inicial usado no modelo, considerandose uma taxa média geométrica de $1,16 \%$.

O modificador de crescimento populacional, $W_{n}$, é uma função adimensional dada pela razão entre o tempo de dobramento da população inicial e o tempo para dobramento da população no ano $n$, ou seja, $\left(W_{\mathrm{n}}=\theta_{q 0} / \theta_{q n}\right)$. Sua utilização deve-se ao ajuste da variável $\theta_{q 0}$ para cada ano, pois esta não possui valores constantes, sendo fortemente influenciada pelas variações das condições socioeconômicas da população no decorrer do tempo. Essa variável está correlacionada com outras, que são: 
Rodrigo Alves Patrício, Natasha Esteves Batista, Thiago do Carmo Sousa, Antonia Débora Sales, Elissandro Monteiro do Sacramento, Lutero Carmo de Lima, T. Nejat Veziroglu

razão adimensional de população,

$Q_{r n}=\frac{Q_{n}}{Q_{0}}$

razão adimensional de PNB ou PIB,

$G_{r q n}=\frac{G_{n} \cdot Q_{0}}{G_{0} \cdot Q_{n}}$

razão adimensional para poluição,

$P_{r n}=\frac{P_{n}}{P_{0}}$

assim, a melhor forma geral de correlação destas variáveis com $W_{n}$ é:

$W_{n}=A-B\left(G_{r q n}\right)^{a}\left(\mathrm{P}_{\mathrm{r} n}\right)^{b}\left(Q_{r n}\right)^{c}-\frac{C}{\left(G_{r q n}\right)^{a}\left(\mathrm{P}_{\mathrm{r} n}\right)^{b}\left(Q_{r n}\right)^{c}}$

em que $A, B, C, a, b$ e $c$ são constantes adimensionais calculadas por ELJRUSHI e VEZIROGLU (1990), utilizando informações estatísticas disponíveis para o mundo inteiro e para a região onde o modelo é aplicado. Dessa forma, a equação (3.5) é escrita como:

$$
W_{n}=1,3-0,22\left(G_{r q n}\right)^{1,0}\left(\mathrm{P}_{\mathrm{r} n}\right)^{0,1}\left(Q_{r n}\right)^{0,5}-\frac{0,08}{\left(G_{r q n}\right)^{1,0}\left(\mathrm{P}_{\mathrm{r} n}\right)^{0,1}\left(Q_{r n}\right)^{0,5}}
$$

em que $W_{n}, G_{r n}, P_{r n}$ e $Q_{r n}$ possuem valores iniciais 1 para o primeiro ano considerado. Como a equação (3.5) foi estimada utilizando-se dados estatísticos para o mundo e algumas sub-regiões, não se justifica sua utilização para a região aqui tratada, no caso, o estado do Ceará. Isso conduziria a uma sub ou superestimativa dos parâmetros dessa região em relação aos do mundo. Por exemplo, para o mundo, foi estimado um crescimento populacional de aproximadamente 1,13\% ao ano (INTERNATIONAL ENERGY AGENCY, 2002) para os primeiros vinte anos, contados a partir do ano 2000. Foi também estimada uma taxa de crescimento do PIB mundial em 3,2\% ao ano (WWI, 2005). Assim, a equação a seguir foi desenvolvida para representar o modificador de crescimento populacional para o estado do Ceará (SACRAMENTO, 2007) na forma:

$$
W_{n}=1,3-0,077\left(G_{r q n}\right)^{1,0}\left(\mathrm{P}_{\mathrm{r} n}\right)^{0,1}\left(Q_{r n}\right)^{0,5}-\frac{0,228}{\left(G_{r q n}\right)^{1,0}\left(\mathrm{P}_{\mathrm{r} n}\right)^{0,1}\left(Q_{r n}\right)^{0,5}}
$$

\subsection{Demanda energética}

A demanda de energia aumenta a uma proporção maior que o crescimento da população, devido ao desejo das pessoas de melhorar seu padrão de vida. Dessa forma, o crescimento da demanda de energia se relaciona ao crescimento populacional e ao desejo das pessoas de melhorar seu padrão de vida. Assim, o tempo para dobrar o crescimento da demanda de energia $\left(\theta_{e t}\right)$ pode ser expresso da seguinte maneira:

$$
\frac{1}{\theta_{e q}}=\frac{1}{\theta_{e}}+\frac{1}{\theta_{q}}
$$

em que $\theta_{e t}$ é o tempo para dobrar a demanda energética, possuindo duas componentes: $\theta_{e}$, que é a parcela do tempo de dobramento da demanda energética devido ao aumento da qualidade de vida dos habitantes da região; e $\theta_{q}$, que é a parcela relacionada com o tempo de dobramento da população. O tempo de dobramento inicial da demanda energética total do mundo é de 36 anos (INTERNATIONAL ENERGY AGENCY, 2002). De posse dos dados anteriormente descritos, calcula-se o valor inicial para o tempo de dobramento da demanda energética devido ao aumento da qualidade de vida dos habitantes da região pela utilização da equação (3.5), encontrando-se o valor de 92 anos para o mundo. 
Espera-se que o consumo de energia seja fortemente influenciado pelo modificador de crescimento populacional $W_{n}$. A relação entre o consumo de energia no ano $t_{n}, E_{n}$, e no ano $t_{n-1}, E_{n-1}$ pode ser expressa como:

$$
E_{n}=E_{n-1} \cdot \exp \left[(\ln 2)\left(\Delta t_{n}\right)\left(W_{n}\right)\left(\frac{1}{\theta_{q 0} V_{q n}}+\frac{1}{\theta_{e 0} V_{e n}}\right)\right]
$$

em que $E_{n}$ e $E_{n-1}$ são as demandas energéticas totais para os anos $n$ e $n-1$ respectivamente. As variáveis $V_{q n}$ e $V_{e n}$ são os modificadores adimensionais para os tempos de dobramentos $\theta_{q}$ e $\theta_{e}$ respectivamente.

A necessidade de energia devido ao aumento populacional deve crescer a uma taxa menor do que o volume de lares e escritórios por pessoa decresça proporcionalmente. Portanto, o modificador $V_{q}$ é uma função leve da razão populacional, logo:

$$
V_{q n}=\left(Q_{r n}\right)^{x}
$$

em que o valor do expoente $x$ assumido é $\leq 0,1$.

A componente $\theta_{e}$, devido aos esforços para melhorar o padrão de vida, tenderia a diminuir com o decréscimo da capacidade de produção das fontes de combustíveis fósseis, pois mais energia seria requerida para a extração desses recursos energéticos. Ela tenderia também a ter seu valor reduzido com o acréscimo no consumo de energia per capita. $\mathrm{O}$ aumento nos preços dos combustíveis fósseis mundiais resultaria em maiores tempos de dobramentos. Consequentemente, o modificador $V_{e}$ pode ser expresso pela seguinte fórmula:

$$
\text { en } \frac{C_{r n} R_{r n}}{r q n}
$$

em que $C r n$ é a razão entre os preços dos combustíveis fósseis e hidrogênio, $\left(R_{r n}=R_{n} / R_{0}\right)$ é a razão entre recursos de combustível fóssil e $E_{r q n}=\left(E_{n} Q_{0} / E_{0} Q_{n}\right)$ é a demanda energética normalizada em relação ao seu valor inicial. Os expoentes $y, z$ e $v$ possuem valores menores ou iguais a 0,1 .

Produto Interno Bruto

O Produto Interno Bruto (PIB) é uma medida da produção total de bens e serviços finais de estado a preço de mercado. Possui uma taxa em geral levemente maior do que a taxa de crescimento de consumo de energia. Pode-se atribuir essa diferença ao contínuo progresso tecnológico no melhoramento das eficiências de conversão de energia e também a produtividade humana. A relação entre o Produto Interno Bruto $G_{n}$ no ano $t_{n}$ e no ano $t_{n-1}$, $G_{n-1}$ pode ser expressa pela seguinte fórmula:

$$
G_{n}=G_{n-1} \exp \left[(\ln 2)\left(\Delta t_{n}\right)\left(W_{n}\right)\left(\frac{1}{\theta_{q 0} V_{q n}}+\frac{1}{\theta_{e 0} V_{e n}}+\frac{1}{\theta_{g 0} V_{g n}}\right)\right]
$$

sendo $G_{n}$ e $G_{n-1}$ os valores do PIB nos anos $n$ e $n-1$, respectivamente. A variável $\theta_{q 0}$ é a componente inicial para o tempo de dobramento do PIB devido aos avanços tecnológicos e está relacionada com os tempos de dobramentos da população, demanda energética e PIB pela seguinte expressão:

$$
\frac{1}{\theta_{g}}=\frac{1}{\theta_{e}}+\frac{1}{\theta_{q}}+\frac{1}{\theta_{g}}
$$

em que $\theta_{g t}$ é o tempo de dobramento do PIB. A variável $\theta_{g}$ tende a decrescer com o aumento do PIB per capita, desde que este último decorra em investimentos em atividades de pesquisas e de desenvolvimento, favorecendo, portanto, o seu contínuo crescimento. Consequentemente, o modificador $V_{g}$ poderia ser expresso por:

$$
V_{g n}=\frac{1}{\left(G_{r q n}\right)^{u}}
$$

em que $u$ é assumido com valores menores ou iguais a 0,1 .

Produção de hidrogênio

O hidrogênio, eventualmente, poderá ser introduzido ao sistema de energia da região de estudo, de forma a substituir gradualmente os combustíveis fósseis. A taxa de produção de hidrogênio adotada é exponencial, tal como a taxa de crescimento exponencial de consumo de energia, podendo então ser expressa pela equação seguinte:

$$
H_{n}=H_{n-1}\left\{\exp \left[\frac{(\ln 2) \Delta t_{n}}{\theta_{h n}}\right]\right\}
$$


em que $H_{n}$ e $H_{n-1}$ representam a produção de hidrogênio nos anos $n$ e $n-1$, respectivamente, e $\theta_{h n}$ representa o tempo de dobramento para produção de hidrogênio. Este último será expresso por:

$$
\theta_{h n}=C_{1}+C_{2}(n-1)
$$

em que $C_{1}$ e $C_{2}$ são constantes independentes. Os valores para essas constantes influenciam diretamente na velocidade com que o hidrogênio substituirá os combustíveis fósseis. São criados dois cenários a partir de valores supostos para essas constantes: um representando a introdução lenta e outro representando a introdução rápida de hidrogênio na matriz energética da região de estudo, em substituição às fontes de energia fóssil.

Três diferentes taxas de tempo para dobrar a quantidade de hidrogênio introduzido são estudadas, com o intuito de mostrar as consequências da introdução de hidrogênio no crescimento populacional, na demanda de energia, no PIB, na poluição etc.:

$$
\begin{aligned}
& \theta_{h n}=2,0+0,2 \cdot(n-1) \\
& \theta_{h n}=2,0+0, \mathbb{Z} \cdot(n-1) \\
& \theta_{h n}=\infty
\end{aligned}
$$

O tempo para dobrar dado pela equação (3.17) representa a taxa de introdução rápida de hidrogênio, seguido por uma taxa de introdução lenta dada pela equação (3.18). No caso em que o sistema de energia continua sendo à base de combustíveis fósseis, ou seja, não se introduz hidrogênio, pode-se dizer que seu tempo de dobramento é infinito.

O hidrogênio produzido será consumido localmente, contribuindo diretamente para a redução do consumo de energia fóssil e, eventualmente, sua importação. Quando comparadas as eficiências de utilização de combustíveis fósseis e de hidrogênio, percebe-se que uma unidade de energia do hidrogênio tem uma maior eficiência de utilização do que uma unidade de energia fóssil. Em outras palavras, há necessidade de uma menor quantidade de energia de hidrogênio do que de energia de combustíveis fósseis para realização do mesmo trabalho. Isso será visualizado nas relações seguintes:

(a) se

$\eta H_{n} \leq E_{n}$

então

$H_{d n}=H_{n}$

$F_{d n}=E_{n}-\eta H_{n}$

$F_{i n}=F_{d n}-F_{p n}$

em que

$H_{n}=$ produção de hidrogênio no ano $t_{n}$;

$\eta$ = razão de eficiência de utilização de hidrogênio em relação ao dos combustíveis fósseis;

$H_{d n}=$ demanda de hidrogênio no ano $t_{n}$;

$F_{d n}=$ demanda de energia fóssil no ano $t_{n}$;

$F_{p n}=$ produção de energia fósssil no ano $t_{n}$;

$F_{i n}=$ importação de energia fóssil no ano $t_{n}$;

sendo $E_{n}$ a demanda energética em atividades que necessitam da energia fóssil na região estudada no ano $n$.

Uma vez que a utilização de hidrogênio apresenta maior eficiência que a utilização de energia fóssil, o fator $\eta$ (razão de eficiência de utilização) é introduzido. Para esse caso, a taxa de produção de hidrogênio é dada pela seguinte equação:

(b) se

$\eta H_{p n}>E_{n}$

então

$F_{d n}=0$ 


$$
H_{n}=\frac{E_{n}}{\eta}
$$

Nesse caso, a taxa de produção de hidrogênio acompanha a demanda de energia para um determinado ano.

\subsection{Preços de energia}

Conforme SACRAMENTO (2007), a demanda de energia, ganho e disponibilidade de fontes de energia são os fatores importantes que afetam os preços de energia. Uma investigação de dados históricos mostra que os preços de fluidos fósseis podem ser correlacionados em termos dos parâmetros acima mencionados, levando em conta a seguinte expressão:

$$
C_{r f h}=0,33+\frac{0,67\left(G_{r w n}\right)^{0,2}\left(F_{r q w n}\right)^{0,5}}{\left(R_{r w n}\right)^{0,5}}
$$

em que $C_{r f n}\left(=C_{f h} / C_{f 0}\right)$ é a razão de preço da energia fóssil, $G_{r w n}\left(=G_{w n} / G_{w 0}\right)$ é a razão entre os valores do PIB mundial, $F_{r q w n}\left(=F_{w n} Q_{w 0} / F_{w 0} Q_{w n}\right)$ é a razão entre os valores do consumo mundial de energia fóssil per capita e $R_{r w n}\left(=R_{w n} / R_{w 0}\right)$ é a razão de fontes de combustível fóssil no mundo.

De maneira similar, a seguinte relação é obtida para os preços mundiais de energia à base de hidrogênio:

$$
C_{r h n}=0,2+\frac{0,8\left(G_{r v n}\right)^{0,2}\left(F_{r q w n}\right)^{0,4}}{\left(H_{r w n}\right)^{0,43}}
$$

em que $C_{r h n}\left(=C_{h n} / C_{h 0}\right)$ é a razão entre os valores de preço de hidrogênio e $H_{r w n}\left(=H_{w n} / H_{w 0}\right)$, a razão de produção de hidrogênio no mundo.

Com o intuito de apresentar a média proporcional dos preços de energia de hidrogênio e fóssil e suas produções, define-se uma razão de preços de energia composta $C_{r c n}$, como apresentado a seguir:

$$
C_{r c n}=\gamma_{f i} \cdot C_{r f n}+\gamma_{h} \cdot C_{r h n}
$$

em que $\gamma_{f n}\left(=F_{w n} / E_{w n}\right)$ é a fração de consumo mundial de combustível fossil e $\gamma_{h n}\left(=H_{w n} / E_{w n}\right)$, a fração de consumo a base de hidrogênio no mundo.

\section{6 Área de célula fotovoltaica e área total do terreno}

A área total do projeto das células fotovoltaicas, $A_{c n}$, é dada por:

$A_{c n}=A_{h n}+A_{w n}$

em que $A_{h n}$ é a área das células fotovoltaicas para a produção de hidrogênio e $A_{w n}$ é a área das células fotovoltaicas para a usina de dessalinização.

Com o propósito de evitar o sombreamento dos painéis fotovoltaicos e permitir atividade agrícola, deve ser deixado certo espaçamento entre os painéis. A área total de terreno para o projeto, $A_{p n}$, é dada por:

$$
A_{p n}=\frac{A_{c n}}{\beta}
$$

em que o termo $\beta$ é um coeficiente que acrescenta à área das células, $A_{c n}$, o espaçamento entre elas, sendo seu valor 0,34 (LUTFI e VEZIROGLU, 1990).

Área total de células fotovoltaicas para a produção de hidrogênio

A área das células fotovoltaicas necessárias para satisfazer a produção total de hidrogênio no ano, $t_{n}$, pode ser calculada pela seguinte equação:

$$
A_{h n}=\frac{H_{n}}{\eta_{p v} \cdot \eta_{e t} \cdot S_{a v}}
$$

sendo $\eta_{p v}$ a eficiência do sistema fotovoltaico, $\eta_{e t}$ a eficiência do eletrolisador e $S_{a v}$ a média anual de insolação por unidade de área nos painéis fotovoltaicos. 
Rodrigo Alves Patrício, Natasha Esteves Batista, Thiago do Carmo Sousa, Antonia Débora Sales, Elissandro Monteiro do Sacramento, Lutero Carmo de Lima, T. Nejat Veziroglu

O parâmetro mais importante de uma célula fotovoltaica é a eficiência de conversão. Grandes eficiências significam mais energia produzida e baixos custos. As maiores causas da ineficiência em células solares são as perdas espectrais vermelhas e azuis. Essas perdas estão associadas à capacidade de uma célula utilizar certa faixa do espectro solar. Outras causas de ineficiência são reflexão, fator de voltagem, elevação da temperatura ambiente, entre outras.

\subsection{2 Área das células fotovoltaicas para dessalinização da água}

Com o objetivo de suprir o eletrolisador com água fresca e para fins de irrigação, a água do mar deve ser dessalinizada usando osmose reversa, na qual o solvente $\left(\mathrm{H}_{2} \mathrm{O}\right)$ deve passar de um meio hipertônico para um meio hipotônico, precisando, obviamente, de energia para realização desse processo. Assim, uma área, $A_{w n}$, adicional de células fotovoltaicas deve ser requerida para gerar eletricidade para a dessalinização da água.

Se $W_{d n}$ é a demanda total de água no ano $t_{n} \mathrm{em} \mathrm{m}^{3} /$ ano e $E_{l}$ é o consumo de energia da usina de dessalinização em $\mathrm{GJ} / \mathrm{m}^{3}$, então:

$$
B_{w n}=E_{1} \cdot W_{d n}
$$

$$
A_{w n}=\frac{B_{w n}}{\eta_{p v} \cdot \eta_{r e} \cdot S_{a v}}
$$

em que $B_{w n}$ é a energia elétrica total requerida no ano $t_{n}$ em GJ e $\eta_{r e}$ é a eficiência do retificador.

\subsection{Capacidade da usina de dessalinização da água}

A relação que representa a demanda de água $\left(W_{d n}\right)$ no ano $t_{n}$ é dada por:

$W_{d n}=W_{h n}+W_{i n}$

em que

$W_{h n}=$ demanda de água para a produção de hidrogênio;

$W_{i n}=$ demanda de água para a irrigação;

$W_{h n}$ e $W_{i n}$ podem ser calculados pelas fórmulas abaixo:

$W_{h n}=W_{1} \cdot H_{n}$

$W_{\text {in }}=W_{2} \cdot A_{a n}$

em que

$W_{1}=$ consumo do eletrolisador por GJ de hidrogênio produzido;

$W_{2}=$ demanda anual de água para a irrigação por unidade de área.

Certa área deverá ser usada para fins agrícolas, deixando certo espaço para vias de acesso, colunas de postes de concreto etc. Assumindo a razão entre a área cultivada de terra $A_{a n}$ e a área total do projeto $A_{p n}$, tem-se que:

$$
A_{a n}=\delta \cdot A_{p n}
$$

Levando em consideração vários parâmetros, como evaporação, coeficiente de cultivo, precipitação efetiva e outros, determina-se um valor médio para a demanda de água para a irrigação da região, onde será proposta a instalação do projeto.

\subsection{Benefícios ambientais}

Um dos benefícios na introdução do sistema de energia à base de hidrogênio solar é a substituição do sistema atual, no qual a energia é proveniente de combustíveis fósseis, fazendo com que se reduza a poluição do ar, as chuvas ácidas e o efeito estufa, os quais resultam em economia, devido à diminuição de danos ao meio ambiente.

No caso em que não se faz a introdução de hidrogênio, o custo dos danos ambientais é:

$D_{e n}=E_{n} \cdot C_{p}$ 
em que

$D_{e n}=$ custos dos danos ambientais no ano $t_{n}$;

$E_{n}=$ consumo de energia no ano $t_{n}$;

$C_{p}=$ custo dos danos ambientais por unidade de energia fóssil consumida.

Após a introdução de hidrogênio, o custo de danos ambientais decresce podendo ser expresso por:

$D_{h n}=\left(F_{d n}+\varepsilon H_{n}\right) \cdot C_{p}$

em que

$D_{h n}=$ custo causado pelo hidrogênio e pelos combustíveis fósseis;

$F_{d n}=$ demanda de combustível fóssil no ano $t_{n}$;

$\varepsilon=$ razão de poluição produzida entre o hidrogênio e os combustíveis fósseis.

A equação para economia de danos ambientais, $S_{e n}$, no ano $t_{n}$ pode ser expressa por:

$S_{e n}=D_{e n}-D_{h n}$

ou

$S_{e n}=\eta_{r} \cdot H_{n} \cdot C_{p}-\varepsilon \cdot H_{n} \cdot C_{p}$

\subsection{Economia devido à maior eficiência obtida com a utilização de hidrogênio}

Existem lucros devido ao aumento da eficiência de utilização de hidrogênio ao se comparar com o combustível fóssil. Levando isso em consideração através dos preços de combustíveis, a equação para essa economia pode ser expressa por:

$S_{u n}=E E_{n} \cdot C_{f n}+\left(H_{n} \cdot C_{h n}-F_{d n} \cdot C_{f n}\right)$

em que

$E E_{n}=$ demanda de energia em atividades que necessitam de combustíveis fósseis;

$C_{f n}=$ preço do combustível fóssil no ano $t_{n}$;

$C_{h n}=$ preço do hidrogênio no ano $t_{n}$.

É possível calcular a que preço o hidrogênio poderá tornar-se competitivo em relação à gasolina, por exemplo. Isto é, quando terá o mesmo custo que a gasolina.

\subsection{Crédito para oxigênio}

Durante o processo de eletrólise da água para a produção de hidrogênio, produz-se também oxigênio, que poderia fornecer ganhos e retornos de capitais ao projeto. Se $S_{o n}$ é o ganho devido à produção paralela de oxigênio, esta pode ser vista na equação a seguir:

$S_{\text {on }}=C_{0} \cdot H_{n}$

em que

$C_{0}=$ crédito para o oxigênio por GJ de hidrogênio produzido.

\subsection{Ganho agrícola}

A renda anual incidida devido à entrada de recursos da produção agrícola no terreno sob os painéis fotovoltaicos pode ser expressa por:

$I_{a n}=\Gamma \cdot A_{a n}$

em que

$I_{a n}=$ renda anual de recursos agrícolas;

$\Gamma=$ renda média de recursos da produção agrícola por unidade de área. 
Rodrigo Alves Patrício, Natasha Esteves Batista, Thiago do Carmo Sousa, Antonia Débora Sales, Elissandro Monteiro do Sacramento, Lutero Carmo de Lima, T. Nejat Veziroglu

\subsection{Ganho na venda de hidrogênio}

A renda anual na venda de hidrogênio pode ser expressa por:

$I_{h n}=C_{h n} \cdot H_{n}$

em que

$I_{h n}=$ renda anual da venda de hidrogênio;

$C_{h n}=$ preço do hidrogênio no ano $t_{\mathrm{n}}$.

\subsection{Investimento de capital}

Os principais itens que demandam certo capital de investimento são os postes de concreto, as células fotovoltaicas, os eletrolisadores, compressores, depósitos, linhas de tubulação e a usina de dessalinização. As correlações que calculam o investimento necessário em cada um dos componentes, para cada ano, serão apresentadas nas subseções seguintes.

\subsubsection{Postes de concreto}

Como mencionado anteriormente, os postes de concreto são usados para suportar os painéis fotovoltaicos. Novos postes serão construídos, a cada ano, para acomodação de painéis adicionais.

Se $A_{p}$ é a área da célula fotovoltaica suportada por postes e $N_{p n}$ é o número total de postes no ano $t_{n}$, então:

$N_{p n}=\frac{A_{c n}}{A_{p}}$

em que $A_{c n}$ fora definido no item 3.6

e se

$C_{1}=$ custo unitário do poste;

$C_{p n}=$ capital requerido para construção de postes no ano $t_{n}$;

$\Delta N_{p n}=$ necessidade de novos postes no ano $t_{n}$;

$\Delta N_{p n}=N_{p n}-N_{p n-1}$;

então

$C_{p n}=C_{1} \cdot \Delta N_{p n}$

\subsubsection{Células fotovoltaicas}

No caso das células fotovoltaicas, o tempo de vida é estimado em 30 anos (ELJRUSHI e VEZIROGLU, 1999).

Sendo

$\Delta A_{c n}=$ novas células fotovoltaicas instaladas no ano $t_{n}$;

$C_{p e n}=$ custo de células fotovoltaicas por unidade de área no ano $t_{n}$;

$C_{p v n}=$ capital total requerido para células fotovoltaicas no ano $t_{n}$;

então

$C_{p v n}=\Delta A_{c n} \cdot C_{p e n}$

\subsubsection{Eletrolisador}

O eletrolisador é o coração do sistema e nele ocorrerá a eletrólise para a devida produção de hidrogênio. O tempo de vida do eletrolisador é estimado em 20 anos (ESPÍNOLA, 2008).

$\mathrm{Se}$

$\mathrm{C}_{2}=$ custo do eletrolisador por GJ de hidrogênio produzido;

$\Delta H_{n}=$ nova produção de hidrogênio;

$\Delta H_{n}=H_{n}-H_{n-1}$; 
$C_{e \mathrm{ln}}=C_{2} \cdot \Delta H$

$C_{e l n}$ é o capital requerido para o eletrolisador no ano $t_{n}$.

Operando a uma alta taxa de corrente elétrica, reduz-se substancialmente a contribuição do custo do eletrolisador. Entretanto, o tempo de vida do eletrolisador, bem como a eficiência de eletrólise, são reduzidos quando o eletrolisador é operado à grande densidade de corrente, o que quer dizer que a otimização dos parâmetros de taxa de operação é necessária (SOUZA, 1994)

\subsubsection{Estocagem, compressão e transporte de hidrogênio}

O tempo de vida de um sistema de armazenamento e transmissão de hidrogênio é de 20 anos (YOUNG, 2006). Assim, se $C_{3}$ representa o custo de armazenamento e transmissão por GJ de hidrogênio, se $C_{3}$ é o custo de estocagem, compressão e transporte por GJ de hidrogênio, então

$C_{s n}=C_{3} \cdot \Delta H$

em que $C_{s n}=$ capital total requerido para estocagem, compressão e transporte no ano $t_{n}$.

\subsubsection{Usina de dessalinização da água}

O tempo de vida estimado para a usina de dessalinização é de 30 anos, logo:

$C_{4}=$ capital requerido para a usina de dessalinização por $\mathrm{m}^{3}$ de água,

$$
\Delta W_{d n}=W_{d n}-W_{d(n-1)}
$$

então

$C_{d n}=C_{4} \cdot \Delta W_{d n}$

em que

$W_{d n}$ foi definido na seção 3.1 .

\subsection{Custos de operação e manutenção (O\&M)}

Os componentes que exigem certo custo de operação e manutenção são as células fotovoltaicas, os eletrolisadores, o sistema de estocagem e compressão e a planta de dessalinização. Os cálculos que relacionam os custos para cada um desses componentes serão dados a seguir:

\subsubsection{Células fotovoltaicas}

Se $C_{5}=$ custo de O\&M por $\mathrm{m}^{2}$ de área de células fotovoltaicas então

$O_{p v n}=C_{5} \cdot A_{c n}$

em que $O_{p v n}=$ custo total de O\&M de células fotovoltaicas no ano $t_{n}$.

\subsubsection{Eletrolisadores}

Se $C_{6}$ representar os custos de O\&M por GJ de hidrogênio produzido, então

$O_{e \ln }=C_{6} \cdot H_{n}$

em que $O_{e l n}=$ custo total de O\&M do eletrolisador no ano $t_{n}$.

\subsubsection{Armazenamento e transporte de hidrogênio}

Se $C_{7}$ representar o custo de O\&M para armazenamento e distribuição por GJ de hidrogênio, então

$O_{s n}=C_{7} \cdot H_{n}$

em que $O_{s n}=$ custo total de O\&M para armazenamento e distribuição de hidrogênio. 
Rodrigo Alves Patrício, Natasha Esteves Batista, Thiago do Carmo Sousa, Antonia Débora Sales, Elissandro Monteiro do Sacramento, Lutero Carmo de Lima, T. Nejat Veziroglu

\subsubsection{Usina de dessalinização}

Se $\mathrm{C}_{8}$ representa o custo de $\mathrm{O \& M}$ por $\mathrm{m}^{3}$ para a usina de dessalinização, então

$$
O_{d n}=C_{8} \cdot W_{d n}
$$

em que $O_{d n}=$ custo total de O\&M na usina de dessalinização no ano $t_{n}$.

\subsection{Impacto ambiental (poluição)}

Atualmente, a poluição atmosférica é causada principalmente pelo uso de combustíveis fósseis. A introdução de hidrogênio no setor de energia em substituição aos combustíveis fósseis tem como efeito a eventual redução da poluição do ar. A equação relacionando a poluição ao consumo de combustível fóssil e hidrogênio pode ser vista a seguir:

$P_{n}=U\left(F_{d n}+\varepsilon H_{p n}\right)$

em que

$P_{n}=$ quantidade de poluição no ano n;

$U=$ poluição por unidade de energia fóssil consumida;

$\varepsilon=$ razão entre poluição produzida pelo hidrogênio por unidade de energia fóssil e a poluição produzida pelos combustíveis fósseis por unidade de energia.

\subsection{Qualidade de vida}

A qualidade de vida cresce com o aumento do Produto Interno Bruto e as reservas energéticas. Contudo, decresce com os aumentos de população e poluição. Usando esses fatores na forma adimensional, o indicador de qualidade de vida, $L_{r n}$, pode ser expresso por:

$$
L_{r n}=\frac{\left(G_{n}\right)}{\left(P_{n}\right) \cdot\left(Q_{n}\right)}
$$

em que $G_{r n}\left(=G_{n} / G_{0}\right)$ é a razão dos valores do PIB, $Q_{r n}\left(=Q_{n} / Q_{0}\right)$ é a razão entre valores da população e $P_{r n}\left(=P_{n} /\right.$ $\left.P_{0}\right)$, a razão entre valores de poluição.

\section{RESULTADOS E DISCUSSÃO}

Para este estudo, três cenários são visualizados: o primeiro é aquele em que o sistema renovável de produção de hidrogênio é introduzido na matriz energética do estado do Ceará de maneira rápida. A taxa de introdução do hidrogênio para substituir os combustíveis fósseis é caracterizada por tempo de dobramento, o que significa o intervalo de tempo necessário para que a produção de hidrogênio dobre em relação ao valor inicial da implementação do sistema. Pela Figura 4.1, observa-se que o tempo de dobramento para o cenário de rápida implementação do hidrogênio é da ordem de 13 anos, ao passo que o tempo de dobramento para o cenário de introdução lenta do hidrogênio é da ordem de 16 anos. Para o caso em que o hidrogênio nunca será introduzido na matriz energética do estado, o tempo de dobramento é assumido como infinito. A introdução do hidrogênio na matriz energética do Ceará, para qualquer um dos dois cenários, foi prevista para o ano de 2010; não obstante, o programa inicia o cálculo dos outros parâmetros a partir do ano 2000.

A Figura 4.2 mostra a projeção da população do Ceará para o intervalo de tempo entre os anos de 2000 e 2070, com a economia do hidrogênio sendo introduzida a partir do ano de 2010 na matriz energética do estado. Independentemente da introdução ou não do hidrogênio, a população chegará a cerca de 13 milhões de habitantes para qualquer um dos cenários, a partir do ano de 2045.

A Figura 4.3 apresenta a projeção da demanda de energia total do estado do Ceará. É observada uma mesma taxa de crescimento da demanda total de energia para os três cenários entre os anos de 2000 e 2035 - neste último, a demanda energética totaliza em torno de 1,5 EJ. Para o ano 2070, ambos os cenários de hidrogênio permitem a demanda energética chegar a 2,3 EJ contra 1,9 EJ para o cenário de não introdução do hidrogênio.

A Figura 4.4 mostra a projeção do PIB per capita do Ceará. Os três cenários evoluem similarmente até o ano de 2030, atingindo o valor aproximado de US\$10.000. A introdução do hidrogênio permite chegar à US\$18.000 na década de 2070, contra US\$ 15.000 para o outro cenário. 
Figura 4.1 - Tempo de dobramento da produção de hidrogênio

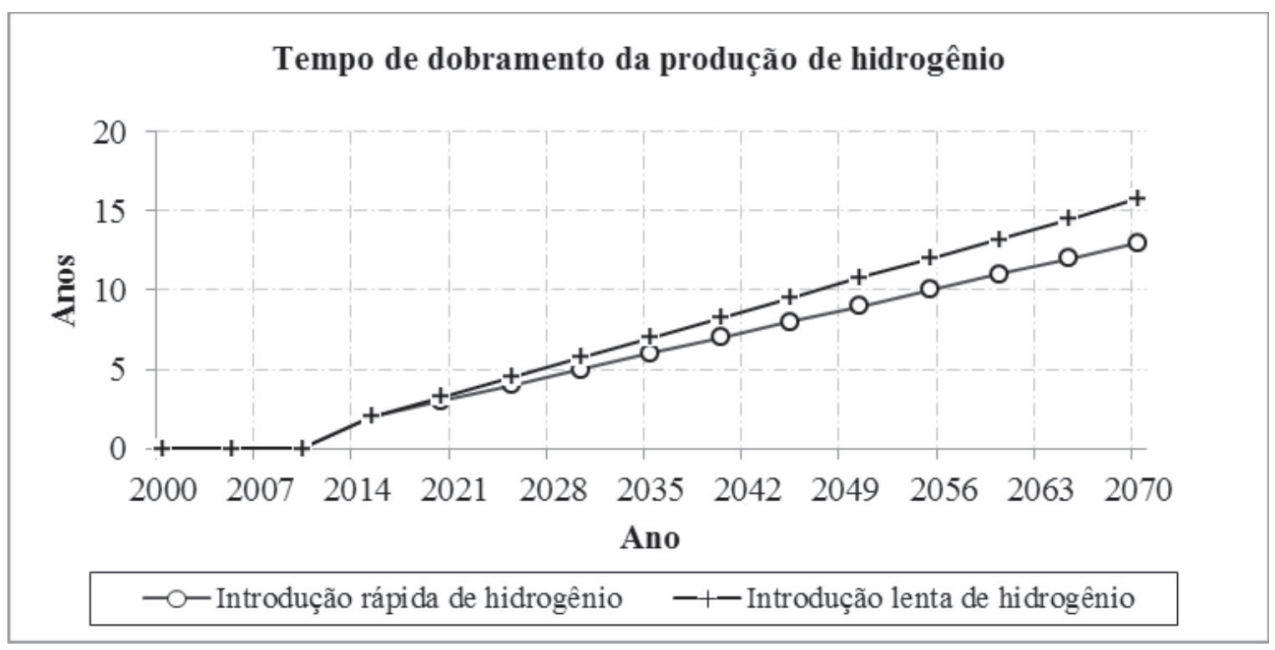

Figura 4.2 - Projeção da população do estado do Ceará

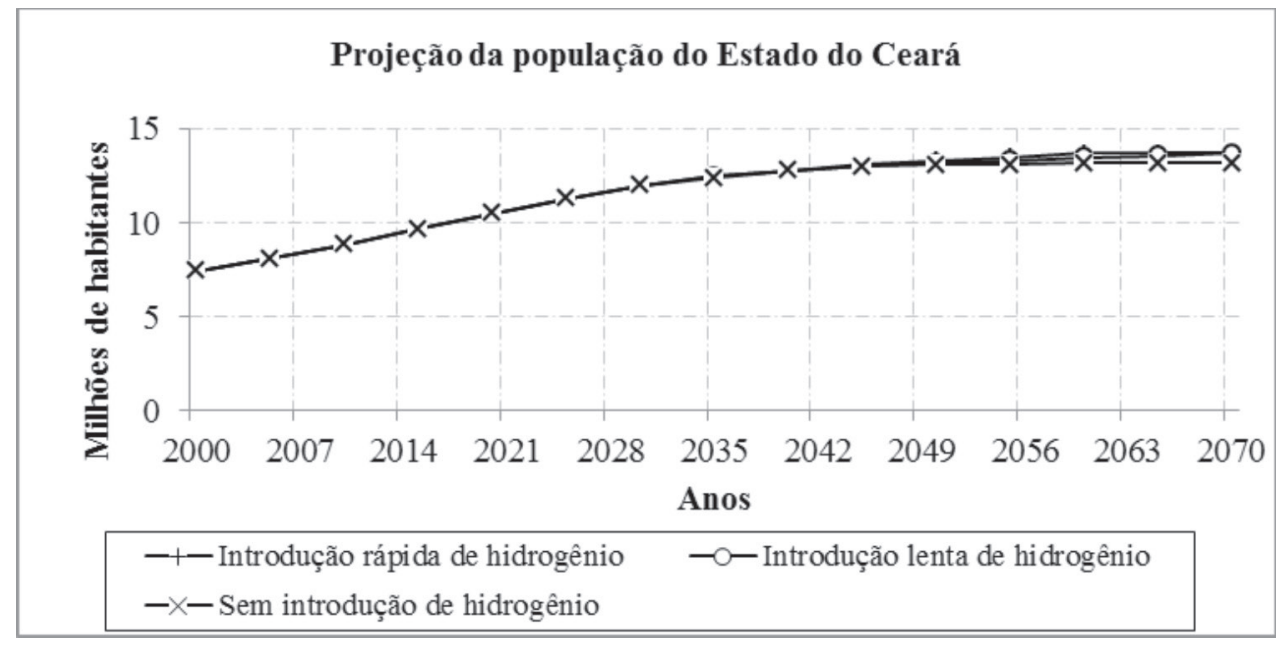

Figura 4.3 - Projeção da demanda energética do estado do Ceará.

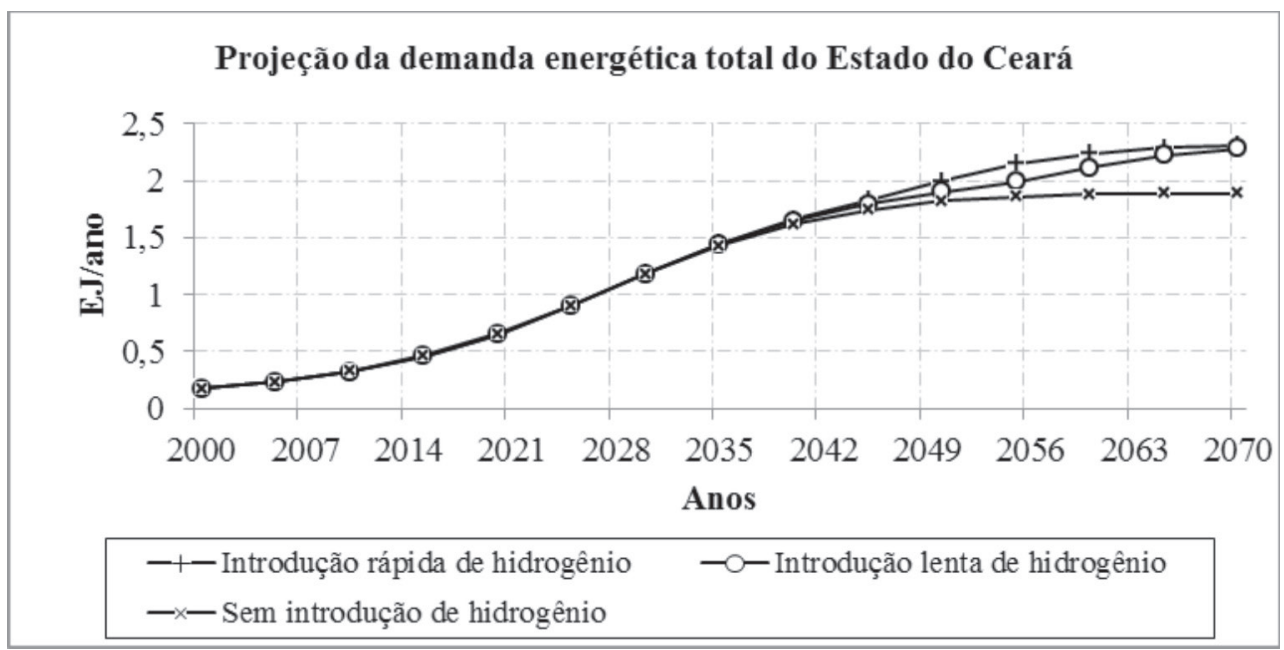


Rodrigo Alves Patrício, Natasha Esteves Batista, Thiago do Carmo Sousa, Antonia Débora Sales, Elissandro Monteiro do Sacramento, Lutero Carmo de Lima, T. Nejat Veziroglu

Figura 4.4 - Projeção do PIB per capita do estado do Ceará.

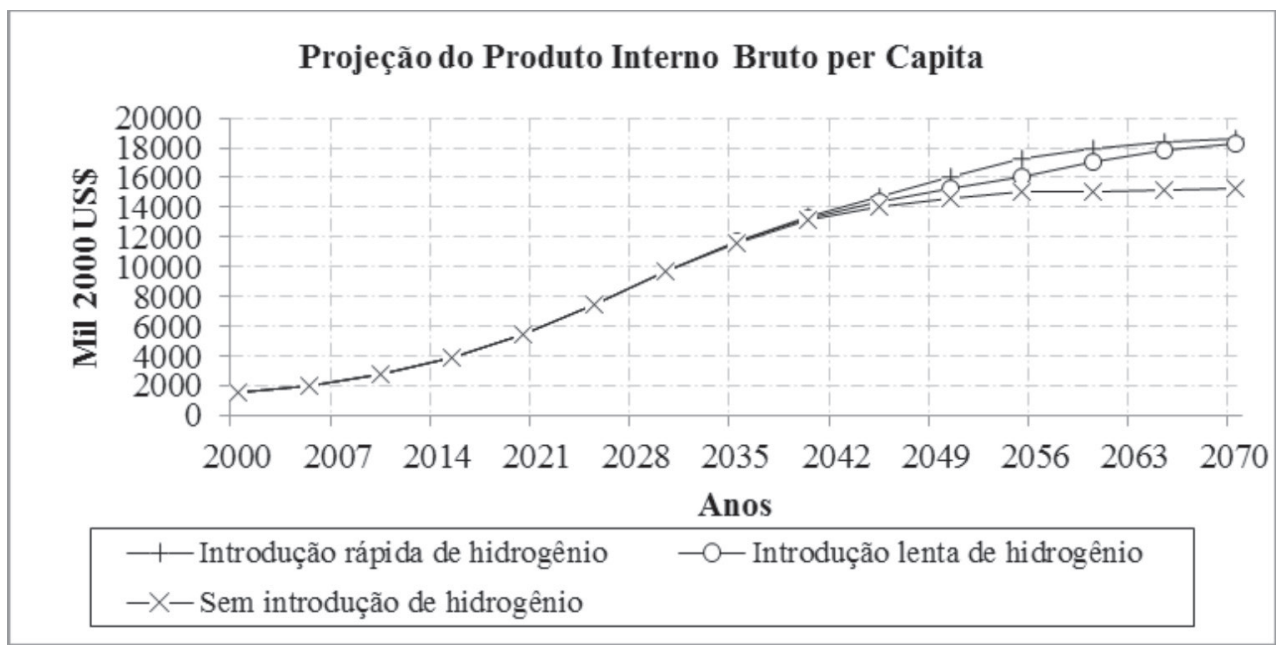

As Figuras 4.5 e 4.6 mostram a introdução do hidrogênio de forma lenta e de forma rápida, respectivamente, comparando com a energia total do gás natural. Na figura 4.5, que representa a introdução lenta de hidrogênio, a demanda de gás natural cresce a partir de 2005 até atingir o valor máximo por volta do ano de 2030, com um valor de 0,026 EJ, e será nula a partir de 2060. Desse período em diante, a produção de hidrogênio irá cobrir toda a produção do gás natural. $\mathrm{Na}$ introdução rápida de hidrogênio, o resultado tem uma ligeira diferenciação de $6 \%$ no pico máximo da demanda do gás natural no mesmo período da introdução lenta, e tornará nulo no ano de 2050; a partir daí, o hidrogênio substituirá a demanda total do gás natural (GN).

Figura 4.5 - Introdução lenta de hidrogênio.

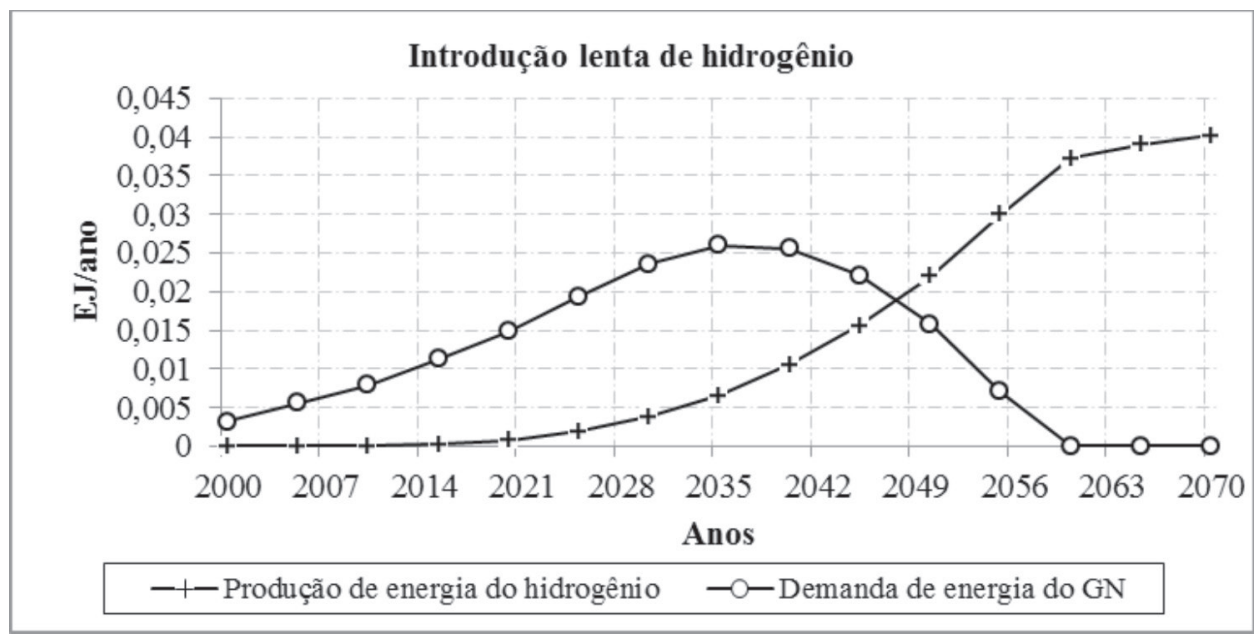


Figura 4.6 - Introdução rápida de hidrogênio.

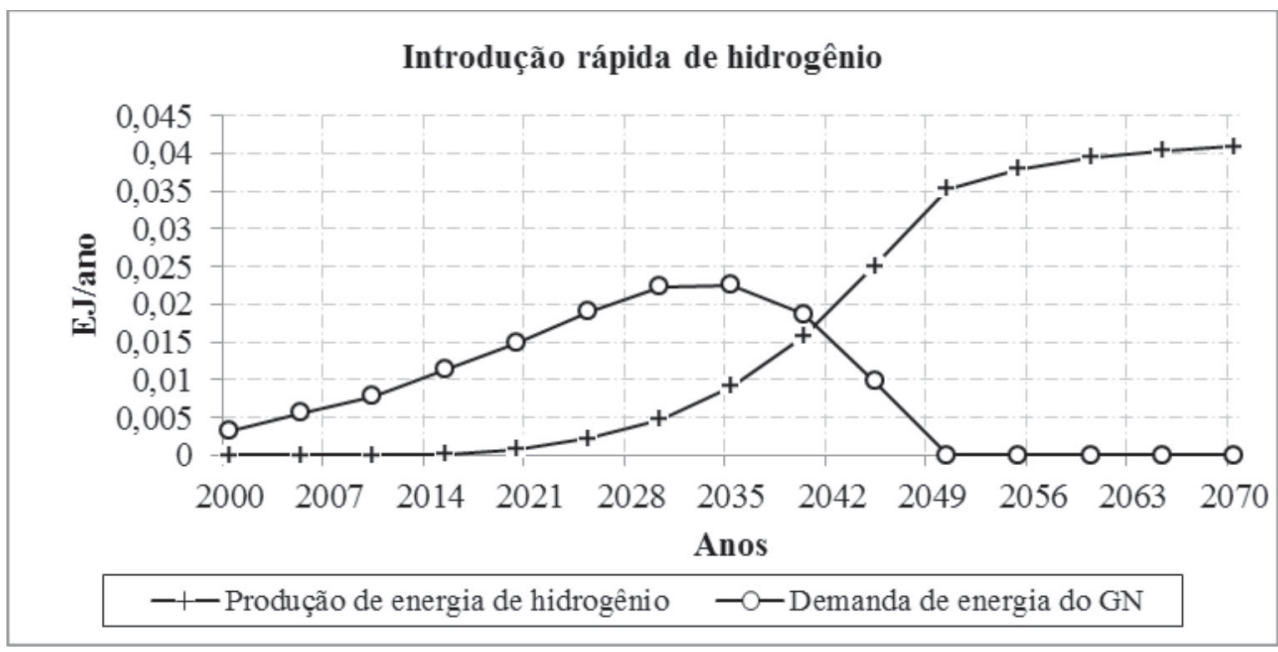

Na Figura 4.7, pode-se observar o comportamento da demanda de gás natural para os dois cenários de introdução do hidrogênio e o cenário de não introdução do hidrogênio na matriz energética do estado do Ceará. Quando o hidrogênio não é introduzido, a demanda de gás natural cresce até o valor de 0,046 EJ, em 2070.

Figura 4.7 - Demanda de gás natural.

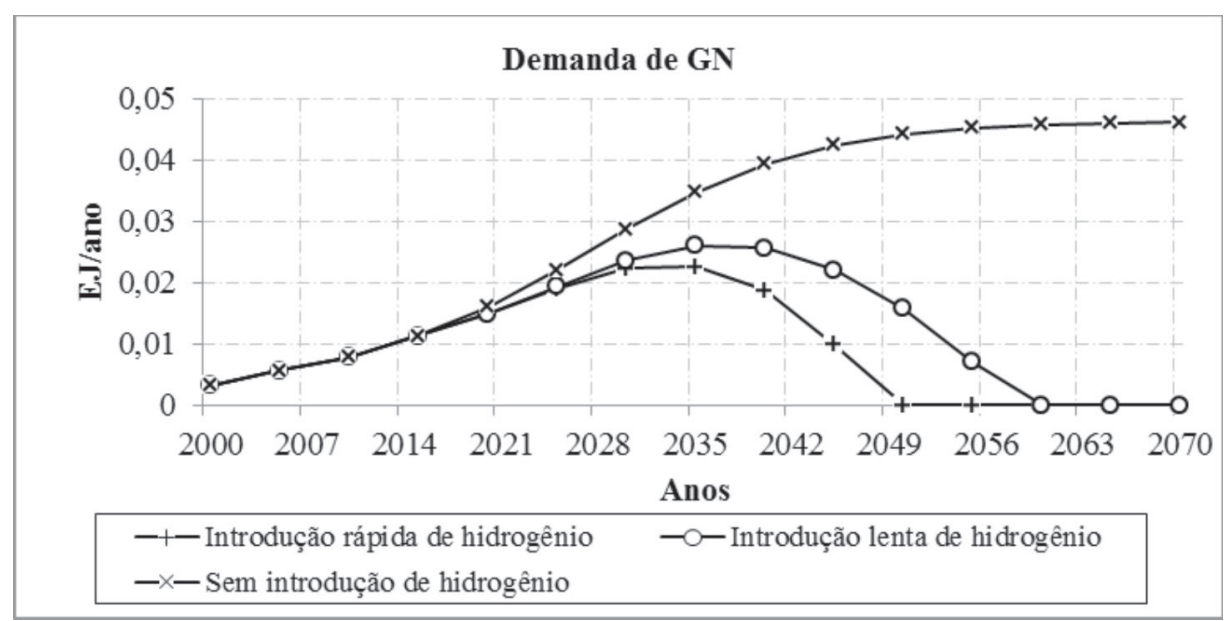

A Figura 4.8 mostra a curva de economia ambiental quando se introduz o hidrogênio na matriz energética do estado, para os dois cenários. A partir dos resultados, observa-se que, em 2015, a economia ambiental é de 27,6 milhões de dólares. Os dois cenários de introdução, lenta e rápida, se estabilizarão a partir de 2060, com uma economia de aproximadamente 625 milhões de dólares, devido à substituição total do gás natural pelo gás hidrogênio. Cada GJ de energia de hidrogênio consumido resulta numa economia com gasto ambiental. 
Rodrigo Alves Patrício, Natasha Esteves Batista, Thiago do Carmo Sousa, Antonia Débora Sales, Elissandro Monteiro do Sacramento, Lutero Carmo de Lima, T. Nejat Veziroglu

Figura 4.8 - Economia Ambiental.

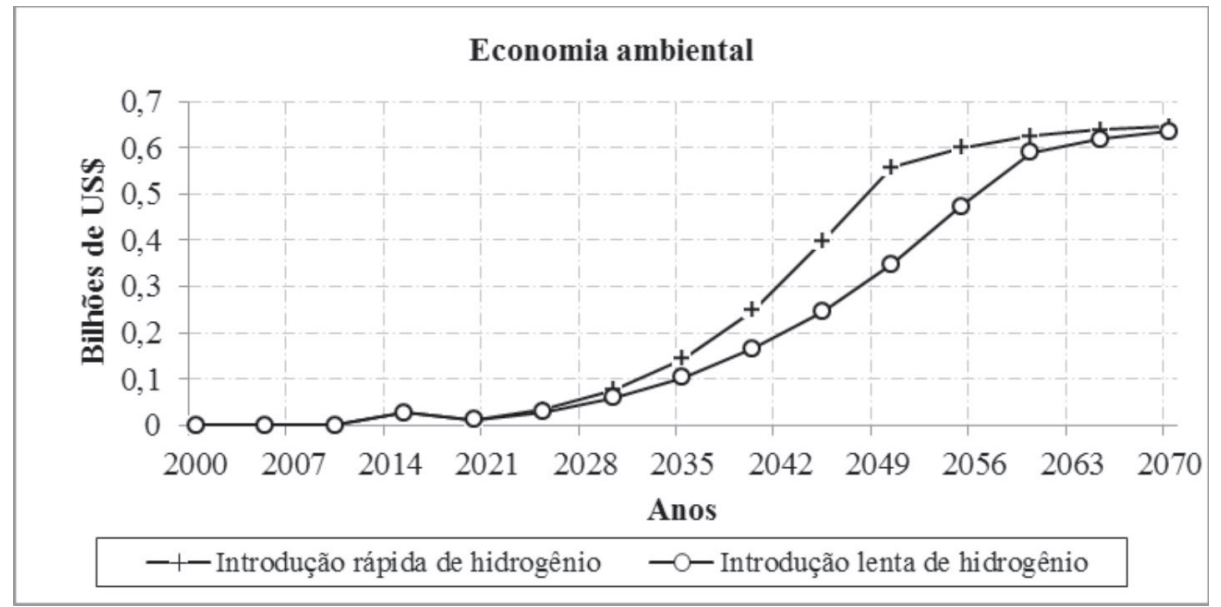

Na produção de hidrogênio através da eletrólise da água, é formado um subproduto, o oxigênio. Este pode ser usado como matéria-prima nas indústrias para sintetizar outros produtos químicos, ou pode ser lançado na atmosfera. A Figura 4.9 representa o crédito gerado com a venda do oxigênio obtido na produção de hidrogênio para o estado do Ceará. No ano de 2065, o crédito gerado na venda do oxigênio, tanto na introdução rápida quanto na introdução lenta de hidrogênio, será de 137 milhões de dólares.

Figura 4.9 - Projeção para o crédito gerado com a venda do oxigênio.

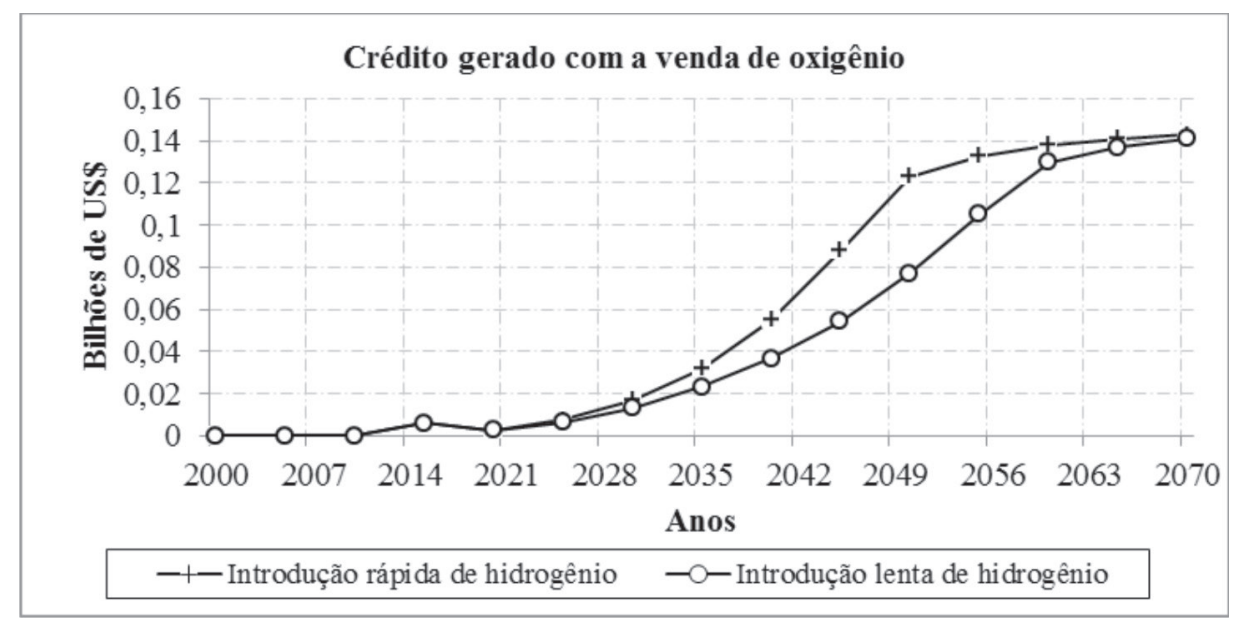

O hidrogênio produzido será vendido para abastecimento do mercado interno, substituindo o gás natural e exportando o seu excedente. A Figura 4.10 apresenta a curva dos montantes obtidos com a negociação do produto hidrogênio. No ano de 2070, obtém-se um ganho de 597 milhões de dólares com os dois cenários em questão.

A produção de hidrogênio do sistema proposto poderá ser realizada a partir da dessalinização da água do mar, aproveitando a vasta área litorânea que o Ceará possui. A Figura 4.11 mostra a demanda de água necessária para a produção de hidrogênio e, possivelmente, para a irrigação das áreas de plantio na região do projeto. A demanda máxima de água estará estável por volta de 2060, com 3,56 bilhões de metros cúbicos por ano. O local a ser instalado o projeto poderá ser no litoral cearense, onde, em alguns lugares, ainda há a necessidade de água potável e para irrigação. 
Figura 4.10 - Ganho na venda de hidrogênio.

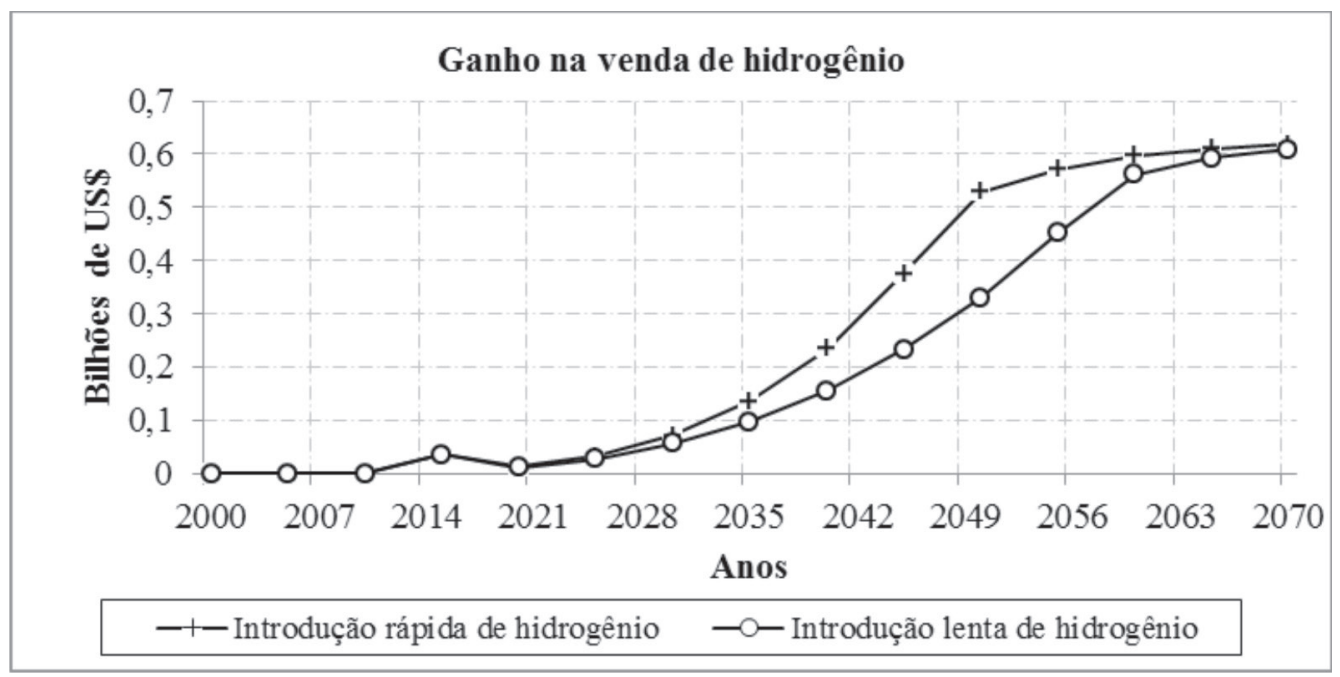

Figura 4.11 - Demanda de água para a usina de dessalinização.

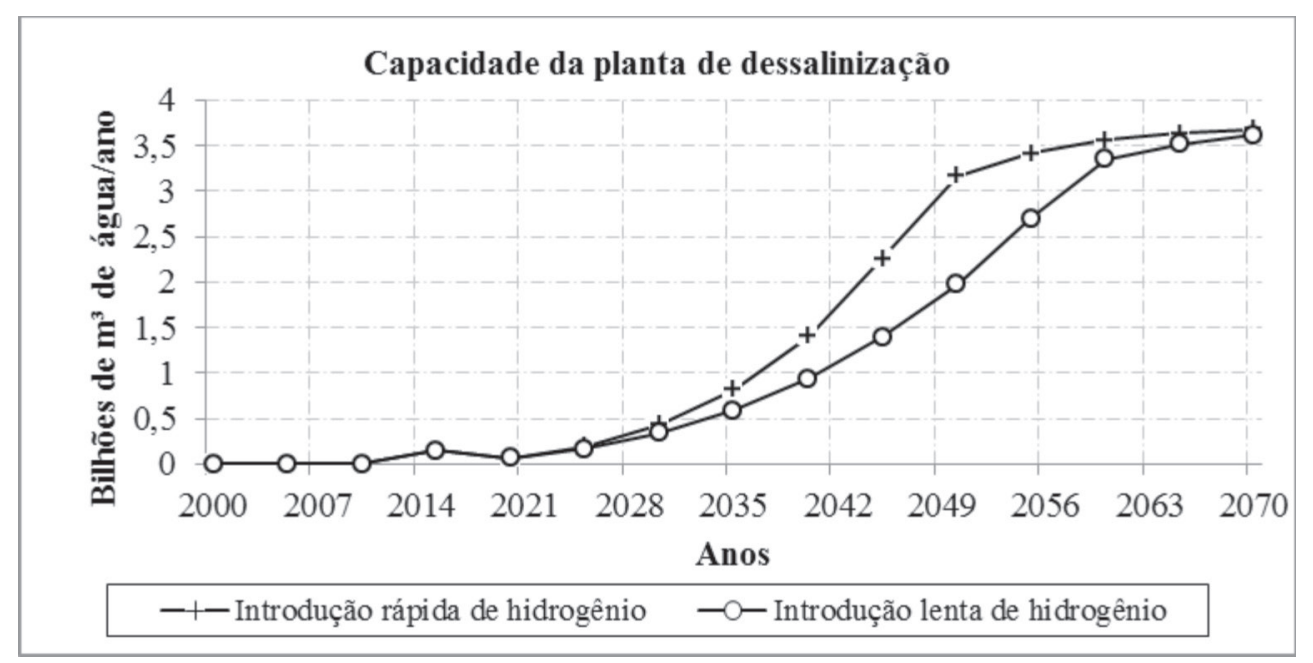

A curva da evolução da quantidade de aerogeradores instalados na área prevista para a implantação do parque eólico é apresentada na Figura 4.12. No intuito de diminuir o impacto ambiental, o espaço entre os aerogeradores, cerca de $99 \%$ do projeto, será destinado à agricultura. Levando em consideração a potência nominal de $2.300 \mathrm{~kW}$ para cada aerogerador, é visto que, para o primeiro ano de produção de hidrogênio, em 2015, seriam necessários 50 aerogeradores - lembrando que a utilização dessa energia seria no horário de baixo pico da demanda de energia. 
Rodrigo Alves Patrício, Natasha Esteves Batista, Thiago do Carmo Sousa, Antonia Débora Sales, Elissandro Monteiro do Sacramento, Lutero Carmo de Lima, T. Nejat Veziroglu

Figura 4.12 - Capacidade do parque eólico.

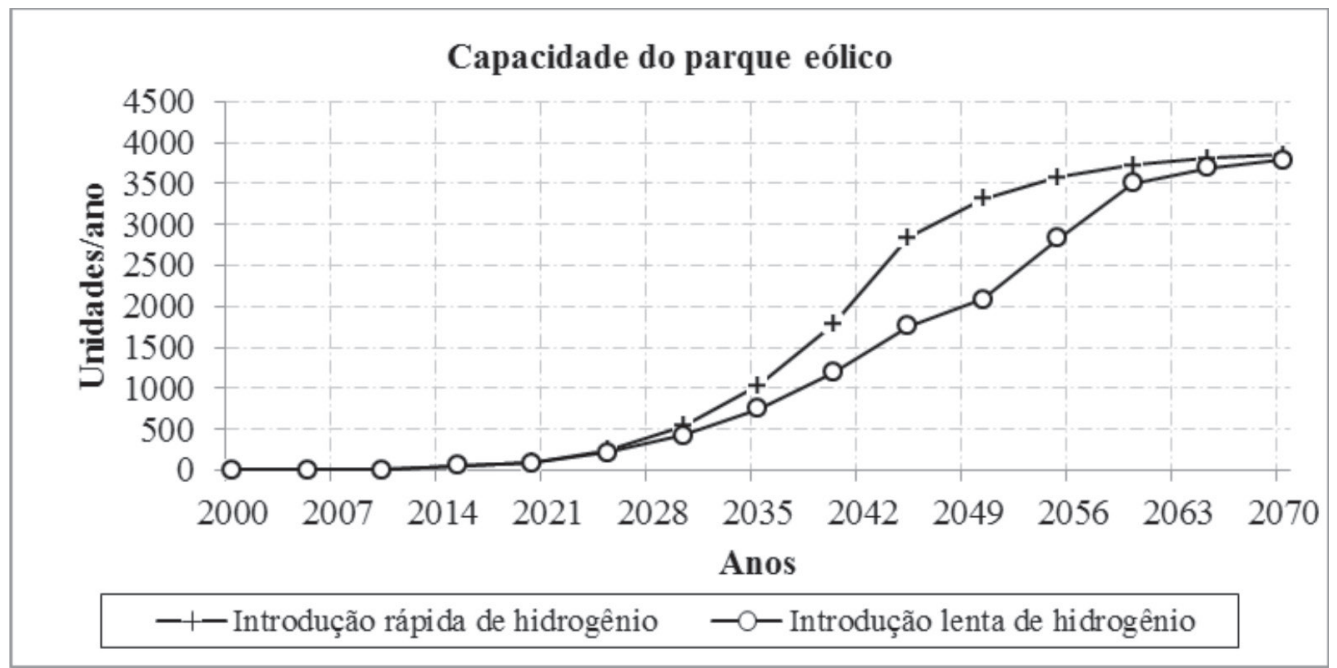

A Figura 4.13 representa a área total do terreno abrangido pelo projeto. No primeiro ano de instalação, o parque ocuparia $21 \mathrm{~km}^{2}$ se houvesse uma introdução lenta de hidrogênio, e $23,7 \mathrm{~km}^{2}$ se a introdução acontecesse de forma rápida. Segundo o Atlas do Potencial Eólico do Estado do Ceará, a área total potencialmente útil, com ventos que tenham uma velocidade média de $7 \mathrm{~m} / \mathrm{s}$, é de $12.426 \mathrm{~km}^{2}$, ou seja, a área ocupada depois da estabilização será de $23 \%$ do total, segundo a projeção.

Figura 4.13 - Área de implantação do parque eólico.

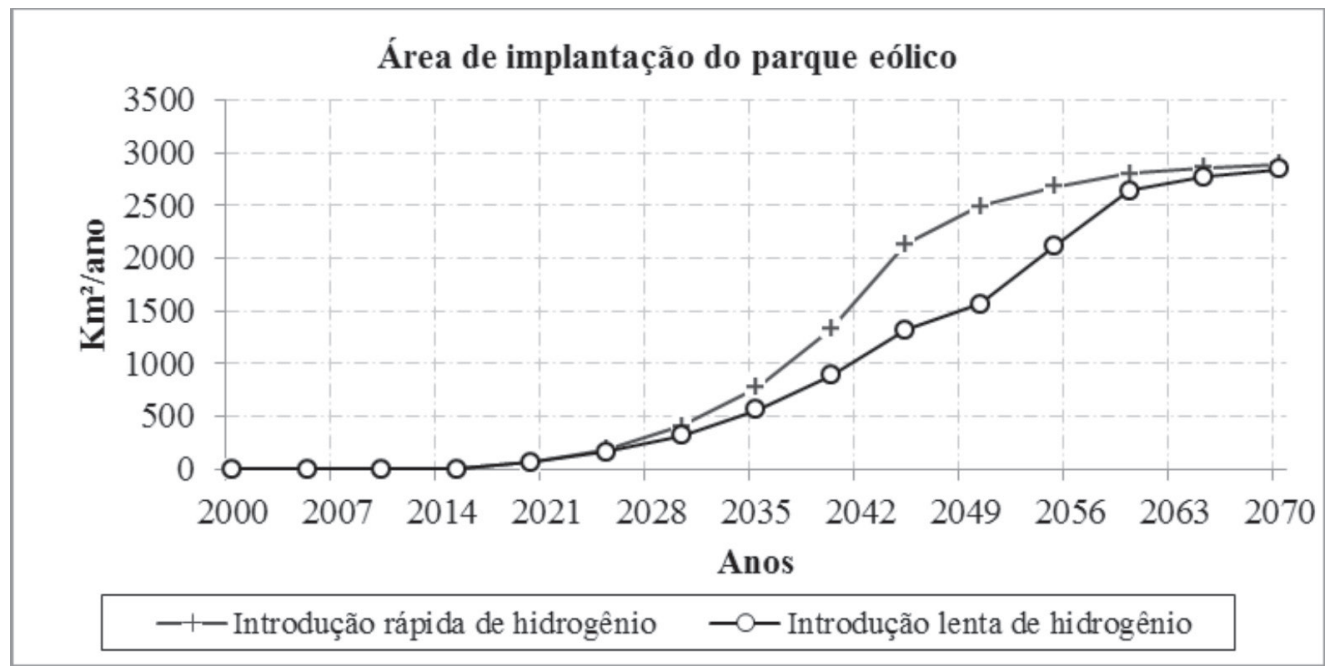

A Figura 4.14 representa o capital requerido para a implantação da usina de dessalinização. É apresentado um cenário de introdução lenta e outro de introdução rápida do hidrogênio, em que cada um deles exibirá dois picos de investimento ao longo do tempo. Isso devido à substituição dos aerogeradores, pois o tempo de vida útil é de aproximadamente 25 anos. 
Figura 4.14 - Capital requerido para a implantação da usina de dessalinização.

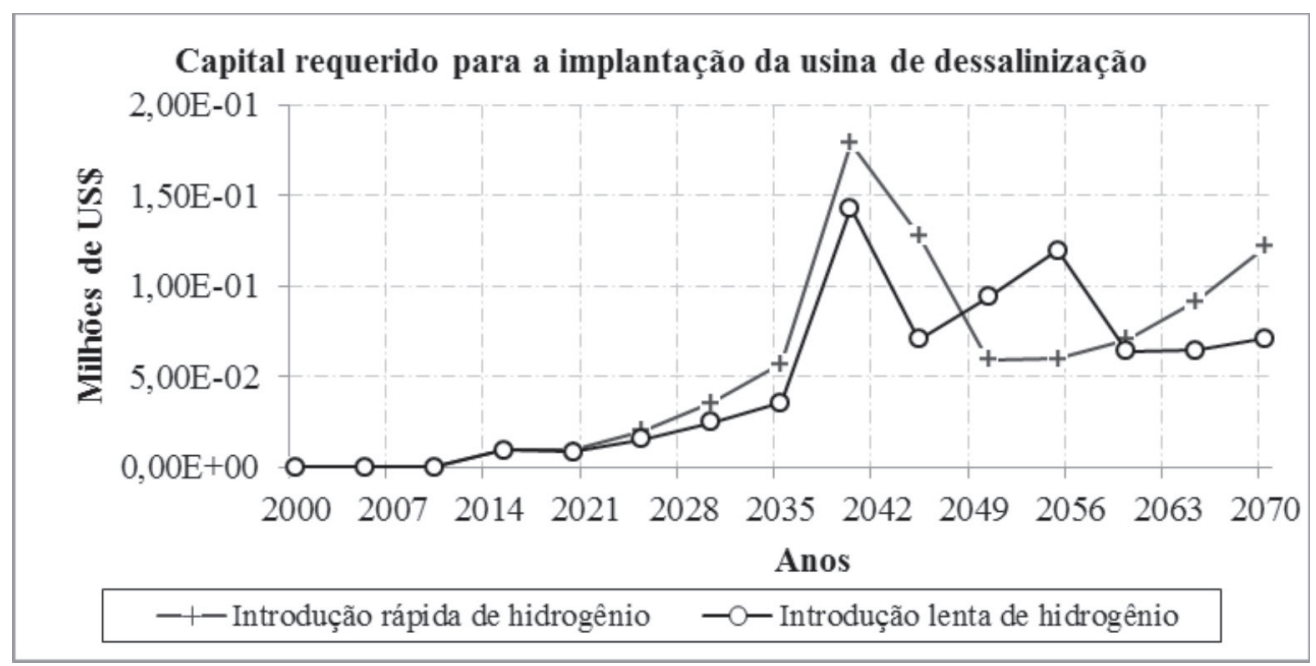

A Figura 4.15 apresenta as curvas de custo para a implementação do sistema de eletrólise da água, mais especificamente a quantidade de eletrolisadores instalados. Notam-se dois picos em cada cenário nos anos 2045, atingindo a cifra de US\$ 8,48 milhões; em 2065, com valor de US\$ 7,70 milhões para aquele que prevê uma introdução mais rápida; nos anos 2055 , atingindo um valor de US\$ 8,03 milhões; e em 2070, com valor de US\$ 5,33 milhões para o que representa a introdução lenta de hidrogênio. Esses picos ocorrem devido às substituições previstas dos eletrolisadores, que têm uma vida útil de 25 anos.

A Figura 4.16 mostra a evolução temporal dos custos com o sistema de estoque e distribuição do hidrogênio produzido. Notam-se dois picos de capital requerido: um em 2045, com US\$ 4,59 milhões; e outro em 2065, com US\$ 4,16 milhões para o caso de inserção rápida de hidrogênio. Eles ocorrem devido à substituição dos equipamentos desse sistema a cada 20 anos, pois esta é a vida útil deles. No caso de introdução mais lenta, os picos ocorrem em 2055, com US\$ 4,34 milhões, e em 2070, com US\$2,88 milhões.

Figura 4.15 - Capital requerido para implementação do sistema de eletrólise da água.

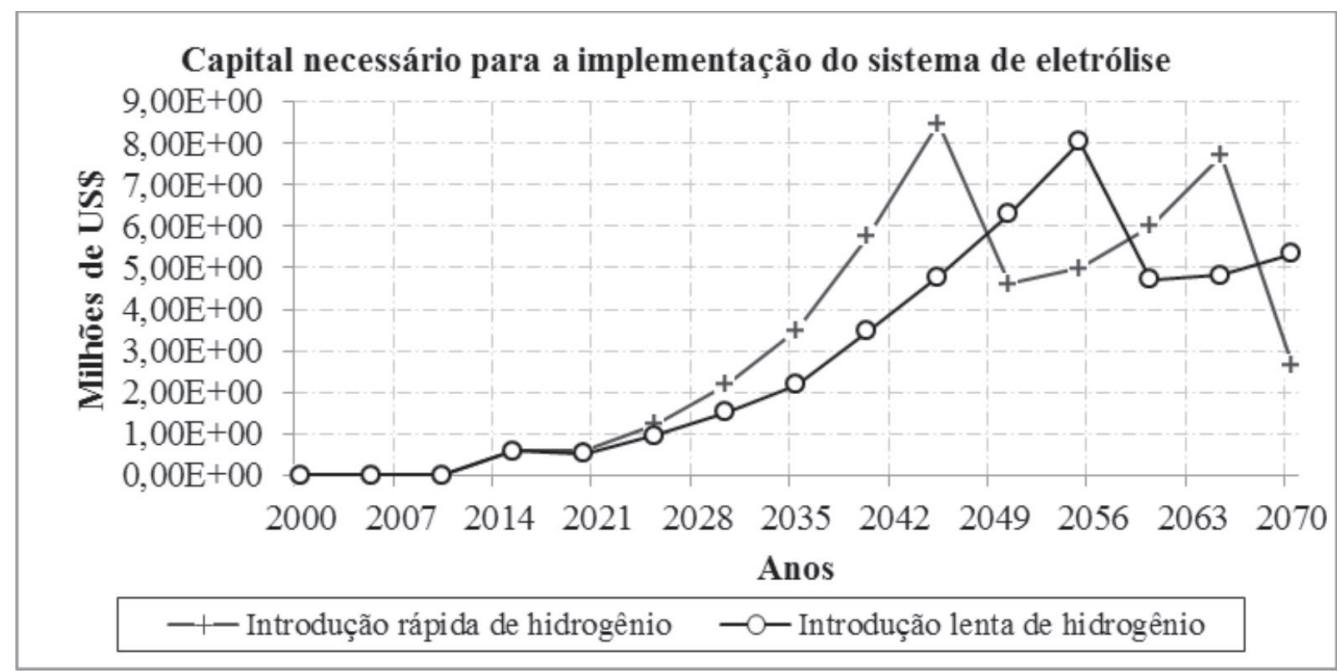


Rodrigo Alves Patrício, Natasha Esteves Batista, Thiago do Carmo Sousa, Antonia Débora Sales, Elissandro Monteiro do Sacramento, Lutero Carmo de Lima, T. Nejat Veziroglu

Figura 4.16 - Capital requerido para implementação do sistema de armazenamento e distribuição de hidrogênio.

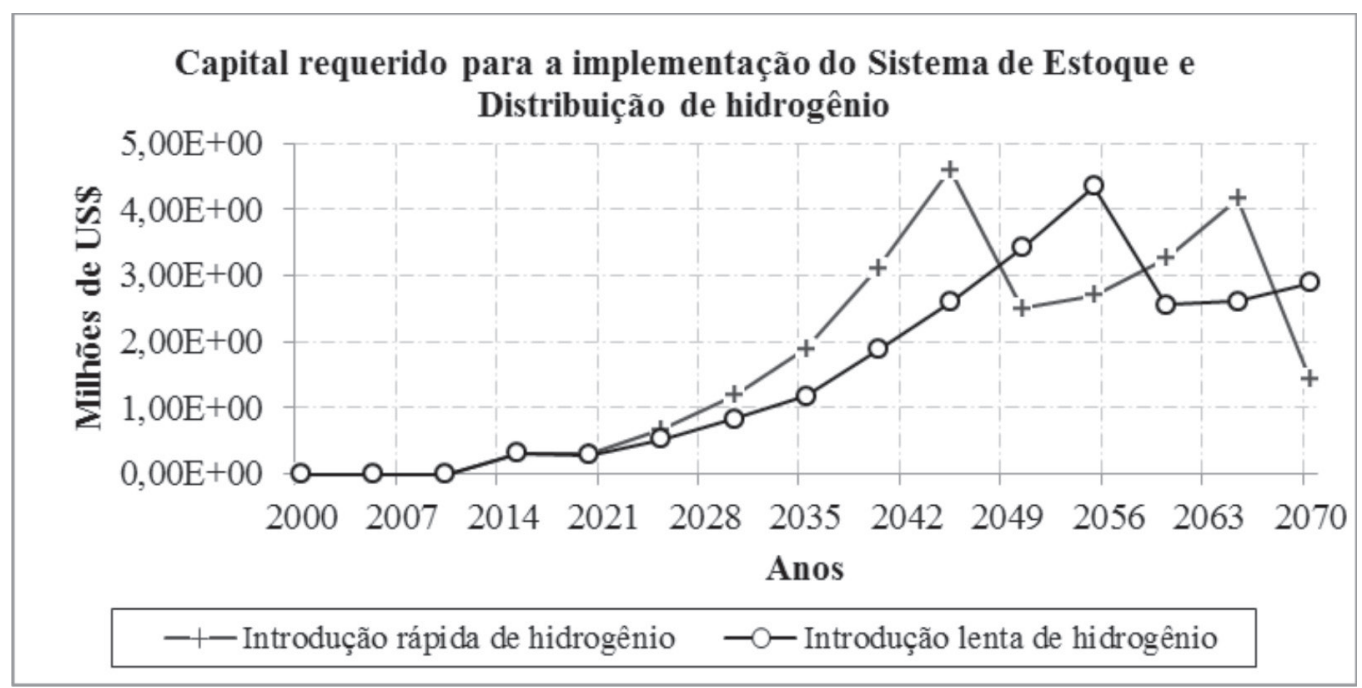

A Figura 4.17 mostra a curva de projeção do capital necessário para a instalação do parque eólico, essencial para a produção de hidrogênio na região estudada. É apresentado um cenário de introdução lenta e outro de introdução rápida de hidrogênio - ambos apresentam picos de investimentos. Na introdução rápida, o investimento é de US\$ 6,55 bilhões em 2050, enquanto na introdução lenta o pico máximo é no ano de 2060, com um investimento de US\$ 5,47 bilhões. A partir desse ano, o valor do investimento decai devido aos avanços tecnológicos, diminuindo assim o preço dos aerogeradores.

Figura 4.17 - Capital necessário para o parque eólico.

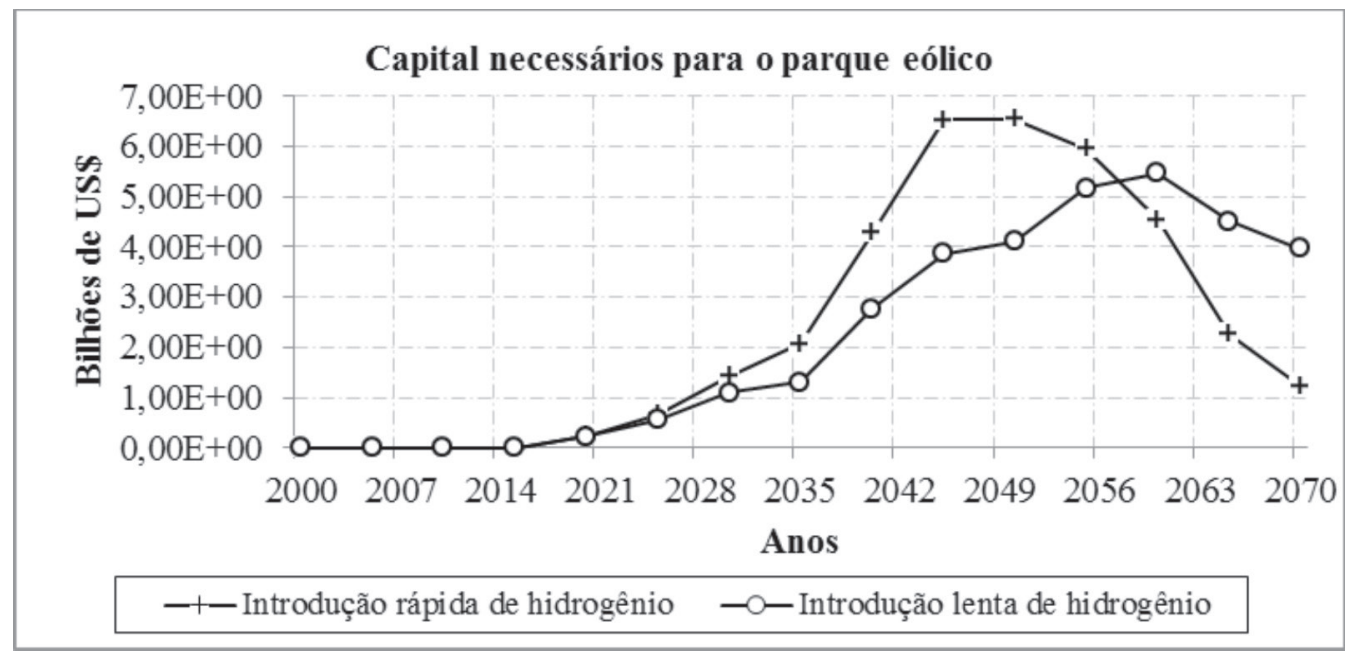

A Figura 4.18 mostra a evolução temporal dos custos de operação e manutenção com os geradores eólicos. Para o caso de introdução rápida de hidrogênio, haverá o valor de US\$ 876 milhões no ano de 2065, enquanto para esse mesmo ano, na introdução lenta, terá um valor de US\$ 849 milhões. Lembrando que esse gasto totaliza $10 \%$ da receita total do sistema proposto. 
Figura 4.18 - Custo de O\&M com o parque eólico.

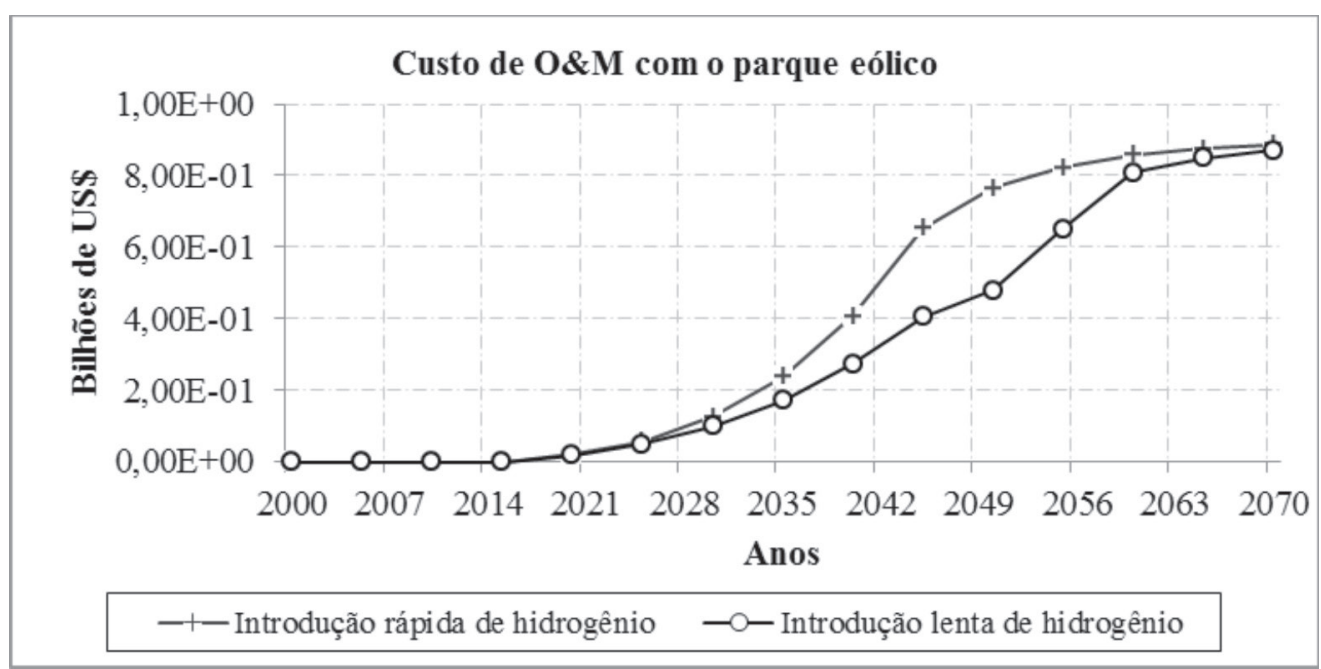

Na Figura 4.19, é apresentado o gráfico do custo de operação e manutenção do sistema de armazenamento e distribuição do hidrogênio produzido. Há um custo inicial para o ano de 2015 no valor de US\$ 137 mil. Os valores se estabilizam no ano de 2065, com aproximadamente US\$16,2 milhões.

Figura 4.19 - Custo de O\&M com o sistema de armazenamento e distribuição do hidrogênio produzido

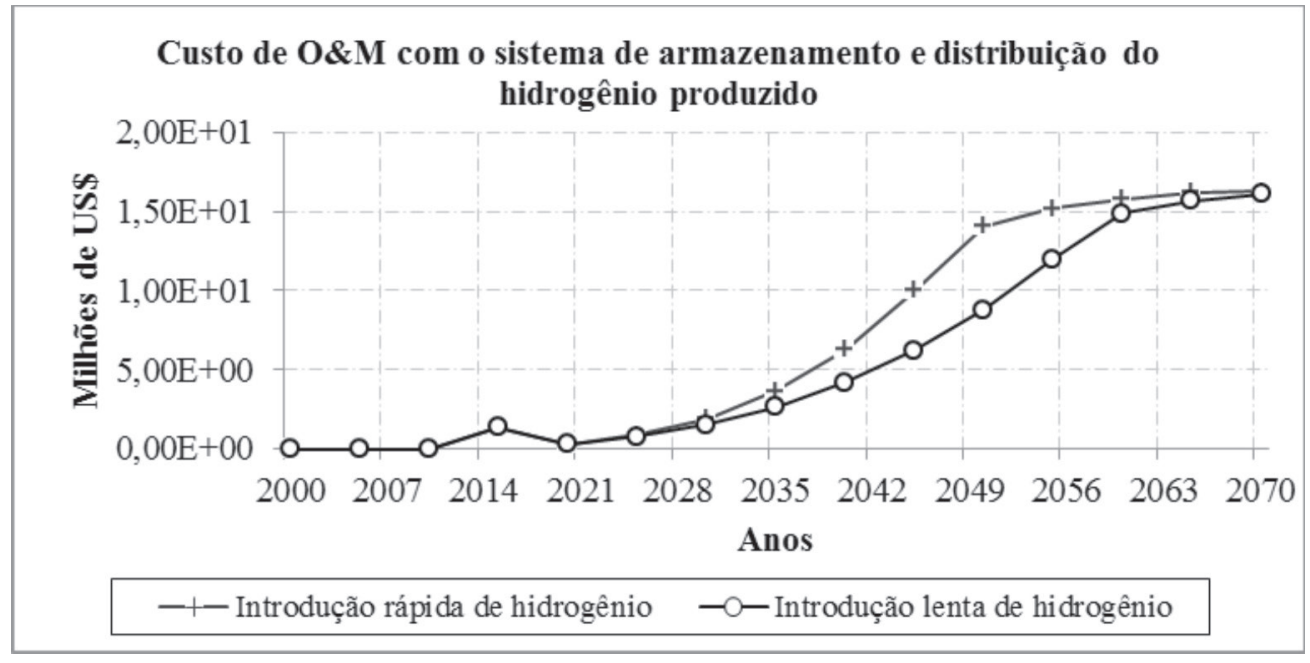

A Figura 4.20 mostra as curvas de custo de O\&M com os eletrolisadores. Nos dois cenários de introdução de hidrogênio, percebe-se um incremento desses custos até alcançarem sua estabilização em 2070, com o valor de US\$27,3 milhões.

A Figura 4.21 mostra as curvas para a variável "razão de poluição" nos três cenários considerados. As curvas apresentam os mesmos valores até o ano de 2015, pois o hidrogênio é introduzido a partir daí. No caso de não inserção de hidrogênio na matriz energética da região, a razão de poluição teria um valor 11 no ano de 2060, bem superior ao valor do inicial considerado, 1. Isso se deve à larga utilização dos combustíveis fósseis. Esse valor estabilizaria nesse mesmo ano, pois a disponibilidade desses combustíveis é reduzida, causando um impacto em sua utilização. No cenário de introdução lenta de hidrogênio, sua curvatura alcançará seu valor máximo de 6,49 em 2040, quando inicia sua queda até 1,05 em 2060, estabilizando-se nesse valor. No cenário de introdução rápida, seu valor máximo é $5,73 \mathrm{em} 2035$, quando iniciará uma queda até $0,996 \mathrm{em}$ 2050, permanecendo estável desse período em diante. Essa característica de estabilização dos valores dessa variável se deve pela redução da demanda de combustíveis fósseis em detrimento da inserção do hidrogênio na matriz energética do estado do Ceará. 
Rodrigo Alves Patrício, Natasha Esteves Batista, Thiago do Carmo Sousa, Antonia Débora Sales, Elissandro Monteiro do Sacramento, Lutero Carmo de Lima, T. Nejat Veziroglu

Figura 4.20 - Custo de O\&M com eletrolisadores.

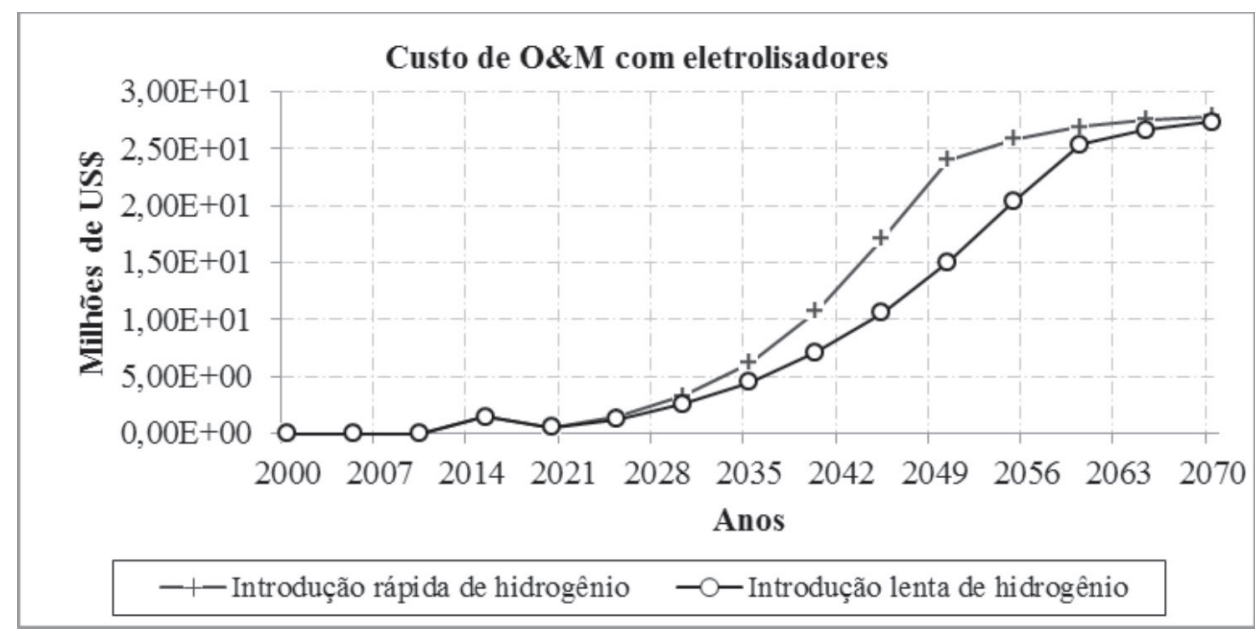

Figura 4.21 - Razão de poluição.

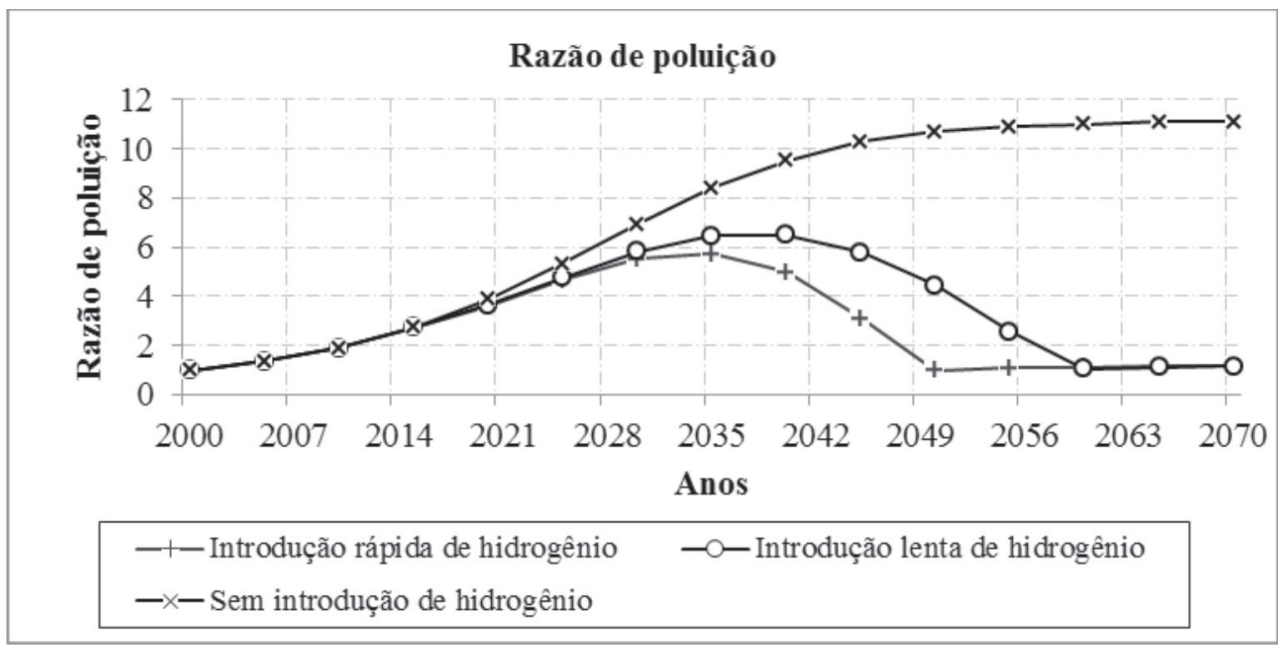

A Figura 4.22 apresenta o comportamento do índice de qualidade de vida. No caso de não inserção do hidrogênio, esse índice cairá de 1 para 0,881, representando numericamente a queda na qualidade de vida dos habitantes da região em análise. No caso de introdução lenta de hidrogênio, a qualidade de vida tende a aumentar de 1 para 10,4 em 2060 , quando estabilizará. No outro caso de inserção de hidrogênio, rápida, ocorrerá um aumento mais célere na qualidade de vida, atingindo o valor de 10,4 no ano de 2050. Esses aumentos ocorrem em virtude da introdução do hidrogênio na matriz energética do estado do Ceará, em substituição ao gás natural, pois sua queima e forma de produção não emitem quantidades consideráveis de poluentes na atmosfera. 
Figura 4.22 - Índice de qualidade de vida.

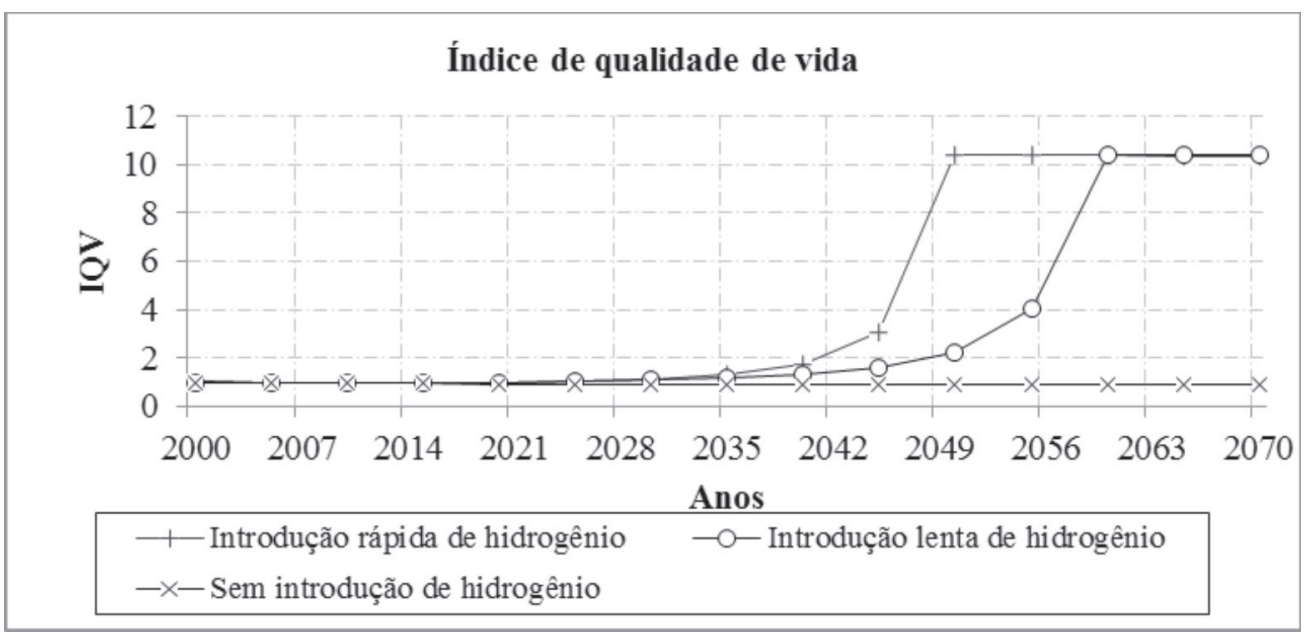

A Figura 4.23 mostra as curvas de capital total investido, custo total de operação e manutenção, gasto total e ganho bruto do sistema, para um cenário de introdução rápida de hidrogênio. $\mathrm{O}$ capital total investido corresponde ao capital gasto com instalação de aerogeradores, eletrolisadores, sistema de estoque, compressão e distribuição, usina de dessalinização etc. O custo total de operação e manutenção seria o gasto com operação e manutenção dos componentes descritos anteriormente. $\mathrm{O}$ gasto total corresponde ao capital total investido mais o custo total de operação e manutenção. O ganho bruto corresponde ao ganho com a venda de hidrogênio, ganho agrícola e crédito com oxigênio. O ganho líquido seria o ganho bruto menos o gasto total. Observa-se na figura que o ganho bruto total no ano 2070 é de US\$ 12 bilhões, enquanto o gasto total é de US\$2,16 bilhões, totalizando um ganho líquido de US\$ 9,84 bilhões.

Figura 4.23 - Custo total do projeto e seu ganho bruto para o cenário de introdução rápida de hidrogênio.

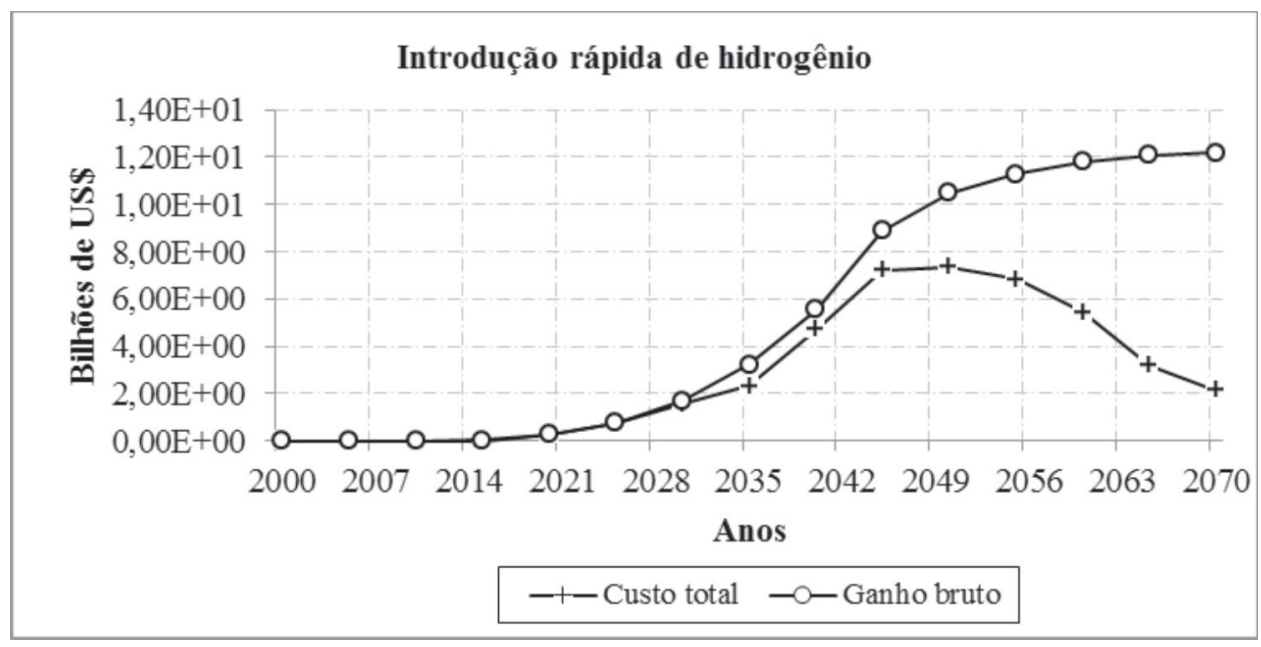

A Figura 4.24 tem o mesmo comportamento da figura anterior, mas a introdução de hidrogênio é lenta. A diferença é que no ano de 2070 o ganho bruto é de US\$12,20 bilhões, e o capital total investido é de US\$ 4,89 bilhões, totalizando um ganho líquido de US\$ 7,31 bilhões, menor que o primeiro cenário. 
Rodrigo Alves Patrício, Natasha Esteves Batista, Thiago do Carmo Sousa, Antonia Débora Sales, Elissandro Monteiro do Sacramento, Lutero Carmo de Lima, T. Nejat Veziroglu

Figura 4.24 - Custo total do projeto e seu ganho bruto para o cenário de introdução lenta de hidrogênio.

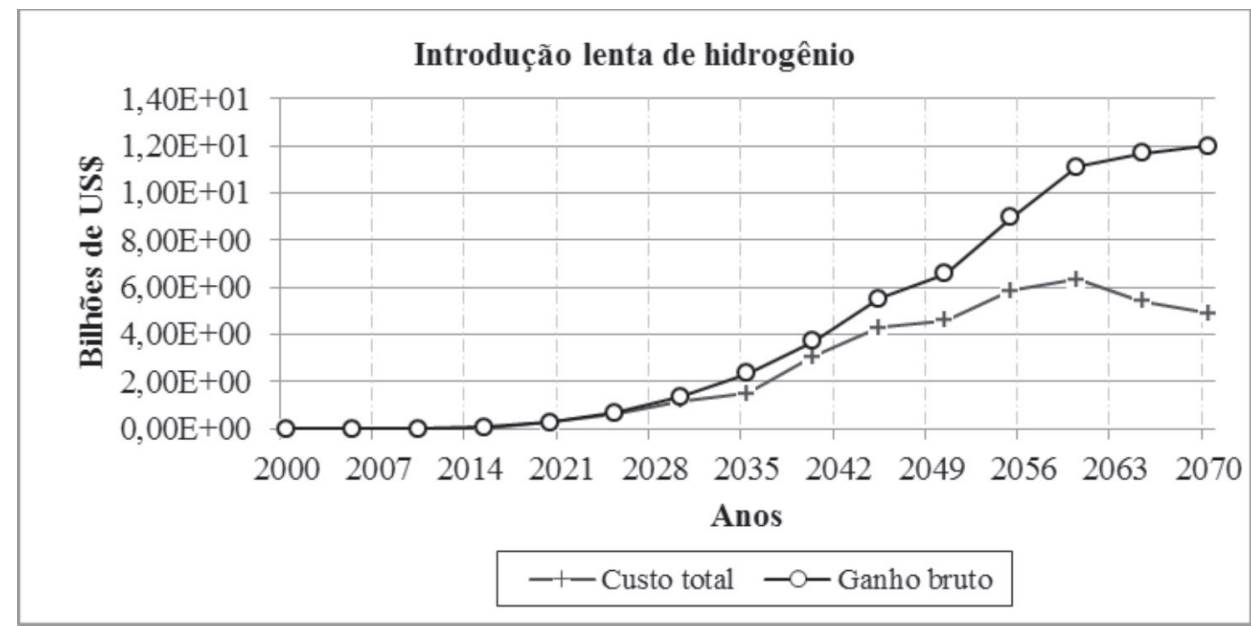

A Figura 4.25 mostra as evoluções temporais dos preços mundiais de hidrogênio e gás natural para o cenário de introdução rápida de hidrogênio. O preço do gás natural, no ano 2000, atingiu um valor de US\$ 8,0/GJ, enquanto o preço do hidrogênio eólico alcança o valor de US\$ 41,8/GJ (DUTTON, 2002). A figura mostra que o preço do hidrogênio passará a ser competitivo por volta do ano 2025. É bem evidente a queda do preço do hidrogênio e o aumento do preço do gás natural, este último alcançando US\$ 15,3/GJ em 2070, enquanto o preço do hidrogênio seria de US\$15,2/GJ. Com essa equivalência de preços, e levando em consideração o fator ambiental, é perceptível que os investimentos na economia do hidrogênio tendem a aumentar, fazendo com que o preço do hidrogênio como combustível tenha um declínio mais acentuado ao longo dos anos.

Figura 4.25 - Evolução dos preços de hidrogênio e do GN.

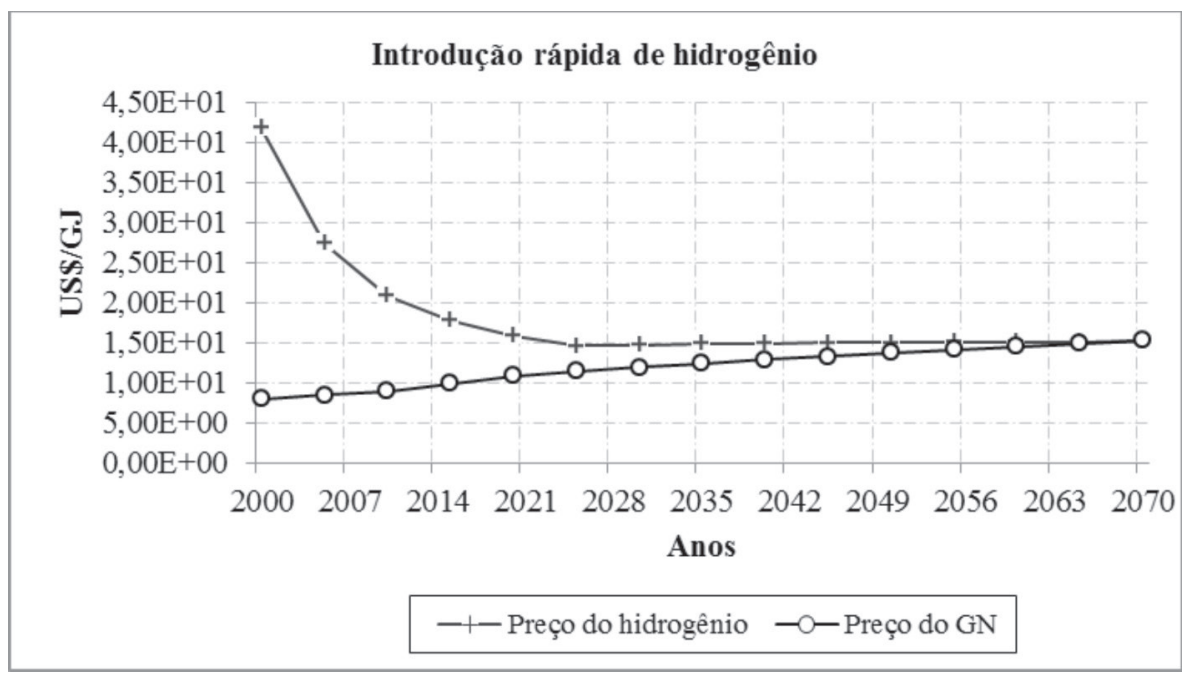

\section{CONCLUSÃO}

A implantação desse sistema visa complementar a matriz energética do estado do Ceará futuramente, já que o gás natural representa cada vez mais uma posição relevante e crescente na economia energética de qualquer país ou estado. Além disso, como no caso do estado do Ceará, estará operante toda a estrutura logística do gás natural, sem maiores prejuízos em seus gasodutos, devido à inserção do hidrogênio, pois há muita similaridade nesse tipo de transporte entre os dois. A substituição do hidrogênio irá ocupar gradativamente o espaço deixado pelo gás natural no estado, contribuindo para diversificação da sua matriz energética 
A geração de hidrogênio irá proporcionar ao Ceará a condição de estado energeticamente autossustentado, permitindo o acréscimo de seu PIB, bem como a melhoria da qualidade de vida da sua população. Os elevados investimentos em energias alternativas, principalmente nas energias eólica e solar, estão impactando na redução dos custos da energia elétrica obtida a partir dessas fontes, proporcionando maior competitividade frente aos sistemas convencionais de geração de energia elétrica.

\section{Referências}

ABDALLAH, M. A. H.; ASFOUR, S. S.; VEZIROGLU, T. Nejat. Solar-hydrogen energy system for Egypt. International Journal of Hydrogen Energy, Amsterdam, v. 24, n. 6, p. 505-517, jun. 1999.

ALMOGREN, S.; VEZIROGLU, T. N. Solar-hydrogen energy system for Saudi Arabia. International Journal of Hydrogen Energy, Amsterdam, v. 29, n. 11, p. 1181-1190, set. 2004.

AMROUCHE, F. et al. Toward hydrogen enriched natural gas "HCNG" fuel on the Algerian road. International Journal of Hydrogen Energy, Amsterdam, v. 36, n.6, p. 4094-4102, 2011.

BARBIR, F. Review of hydrogen conversion technologies. Hemijska Industrija, v. 53, n. 12, p. 426-433, 1999.

Centro de Gestão e Estudos Estratégicos. Estruturação da economia do hidrogênio no Brasil. Disponível em: <http:// www.cgee.org.br/cncti3/Documentos/Seminariosartigos/Areasintnacional>. Acesso em: 06 jul. 2010.

CONTRERAS, A. et al. Solar-hydrogen: an energy system for sustainable development in Spain. International Journal of Hydrogen Energy, Amsterdam, v. 24, n. 11, p. 1041 - 1052, nov. 1999.

LIMA, L. C. de. A solar-hydrogen energy system for the northeast of Brazil. Report of the CAPES/FULBRIGHT Scholar Program, University of Miami, Florida, USA, 1991.

LIMA, L. C. de; VEZIROGLU, T. N. Long-term environmental and socio-economic impact of a hydrogen energy program in Brazil. International Journal of Hydrogen Energy, Amsterdam, v. 26, n. 1, p. 39 - 45, jan. 2001.

DICKINSON, R. R. et al. Alternative carriers for remote renewable energy sources using existing CNG infrastructure. International Journal of Hydrogen Energy, Amsterdam, v. 35, n.3, p. 1321-1329, fev. 2010.

DUTTON, A. G. A review of potential hydrogen production and delivery cost. Energy Research Unit, CLRC Rutherford Appleton Laboratory, 2002. 41 slides. Disponível em: <http://www.technology.stfc.ac.uk/H2NET/PDFs/Systems/ hydrogen_pres005_h2net.pdf $>$. Acesso em: 14 jul. 2011.

ELJRUSHI, G. S.; VEZIROGLU, T. N. Solar-hydrogen energy system for Libya. International Journal Hydrogen Energy, Amsterdam, v. 15, n. 12, p. 885 - 894, dec. 1990.

ESPÍNOLA, M. Estudo da viabilidade técnica e econômica do aproveitamento da energia vertida turbinável da usina hidroelétrica de itaipu para a síntese de amônia. Campinas: UNICAMP, 2008. 129 p. Dissertação (Mestrado) - Programa de Pós-Graduação em Planejamento de Sistemas Energéticos, Faculdade de Engenharia Mecânica, Universidade Estadual de Campinas, Campinas, 2008.

HAESELDONCKX, D.; D'HAESELEER, W. The use of the natural-gas pipeline infrastructure for hydrogen transport in a changing market structure. International Journal of Hydrogen Energy, Amsterdam, v. 32, Issues 10-11, p. 13811386, jul.-ago. 2007.

HIS, S. Hydrogen: an energy vector for the future. Panorama 2004. Disponível em: <http://www.ifp.com/content/ download/57523/1274810/file/IFP-Panorama04_11-HydrogeneVA.pdf>. Acesso em: 14 jul. 2010.

KAZIM, A.; VEZIROGLU, T. N. Utilization of solar-hydrogen energy in the UAE to maintain its share in the word energy market for the 21st century. Renewable Energy, Amsterdam, v. 24, n. 2, p. 259 - 274, out. 2001.

LUTFI, N.; VEZIROGLU, T. N. A clean and permanent energy infrastructure for pakistan: solar-hydrogen energy system. International Journal of Hydrogen Energy, Amsterdam, v. 16, n. 3, p. 169 - 200, s.d., 1991.

MA, F. et al. Twenty percent hydrogen-enriched natural gas transient performance research. International Journal of Hydrogen Energy, Amsterdam, v. 34, 15, p. 6523-6531, ago. 2009.

MARTÍNEZ, P. et al. Life cycle greenhouse emissions of compressed natural gás-hydrogen mixtures for transportation in Argentina. International Journal of Hydrogen Energy, Amsterdam, v. 35, n.11, p. 1- 6, jun. 2010. 
Rodrigo Alves Patrício, Natasha Esteves Batista, Thiago do Carmo Sousa, Antonia Débora Sales, Elissandro Monteiro do Sacramento, Lutero Carmo de Lima, T. Nejat Veziroglu

OGDEN, J. Economia movida a Hidrogênio. Scientific American Brasil, São Paulo, v.1, n. 53, p. 72 - 79, out. 2006.

POWER, S. Aplicação de painéis solares. Disponível em: <http://www.projetabrasil.com.br/fotovoltaico/ Aplicacaopaineisolares.pdf > . Acesso em: 13 jul. 2010.

SACRAMENTO, E. M. et al. A hydrogen energy system and prospects for reducing emissions of fossil fuels pollutants in the Ceara state - Brazil. International Journal of Hydrogen energy, Amsterdam, v. 33, n. 9, p. 2132 - 2137, maio 2008.

SACRAMENTO, E. M. et al. A solar-wind hydrogen energy system for the Ceará state - Brazil. International Journal of Hydrogen Energy, Amsterdam, v 33, n. 20, p. 5304 - 5311, out. 2008.

SACRAMENTO, E. M. Um sistema de energia a hidrogênio-solar-eólico para o estado do Ceará. 2007.163 f. Dissertação (Mestrado em Ciências Físicas Aplicadas) - Universidade Estadual do Ceará, Fortaleza, 2007.

SALES, A. D. Um sistema de energia a hidrogênio eólico para a eventual substituição do gás natural no estado do Ceará. 2010. 114 p. Dissertação (Mestrado em Ciências Físicas Aplicadas) - Universidade Estadual do Ceará, Fortaleza, 2010.

SOUZA, S. N. M. Análise de um sistema a hidrogênio-solar para o Brasil: aspectos técnicos, sociais e econômicos. 1994. 187 p. Dissertação (Mestrado Mestrado em Engenharia Mecânica) - Universidade Federal de Uberlândia, Uberlândia, 1994.

TABKHI, F. et al. Mathematical framework for modelling and evaluating natural gás pipeline networks under hydrogen injection. International Journal of Hydrogen Energy, Amsterdam, v. 33, n.21, p. 6222-6231, nov. 2008.

YOUNG, D. C.; MILL, G. A.; WALL, R. Feasibility of renewable energy storage using hydrogen in remote communities in Bhutan. International journal of hydrogen energy, Amsterdam, v. 32, n. 8, p. 997-1009, jul. 2006.

Sobre os Autores

\section{Rodrigo Alves Patrício}

Licenciado em Física, Universidade Estadual do Ceará - UECE. Atualmente é Professor de Física da UNIFOR e participa também de atividades de pesquisa na área de energias renováveis, como energia solar e eólica, com ênfase na Economia do Hidrogênio.

\section{Natasha Esteves Batista}

Licenciada em Física pela Universidade Estadual do Ceará. Atualmente é aluna do Curso de Mestrado Acadêmico em Ciências Físicas Aplicadas na Universidade Estadual do Ceará - UECE, onde participa de atividades de pesquisa na área de energias renováveis, como energia solar e eólica, com ênfase na Economia do Hidrogênio. Aluna de Engenharia Elétrica na Universidade de Fortaleza - UNIFOR.

\section{Thiago do Carmo Sousa}

Graduando em Física Bacharelado pela Universidade Estadual do Ceará - UECE. Foi bolsista do programa PIBIC/CNPq no ano de 2013, realizando estudos dos sistemas fotovoltaicos conectados na rede elétrica do Centro de Energias Alternativas e Meio Ambiente - CENEA. Foi monitor da disciplina de Termodinâmica pelo programa de Monitoria Acadêmica - PROMAC durante o ano de 2014. Atualmente é bolsista do programa PIBIC/CNPq da UECE.

\section{Antonia Debora Sales}

Possui graduação em Licenciatura Plena em Química pela Universidade Estadual do Ceará (2007). Mestrado em Ciências Físicas Aplicadas (2010) pela Universidade Estadual do Ceará e Doutorado em Biotecnologia pela a Universidade Estadual do Ceará (2015). Tem experiência nas áreas de Bioquímica e Biologia Celular e Molecular. 


\section{Elissandro Monteiro do Sacramento}

Eletrotécnico, Físico e Engenheiro Mecânico, possuindo o título de Mestre em Ciências Físicas Aplicadas pela Universidade Estadual do Ceará (2007), atualmente cursa o doutorado em Engenharia Elétrica na Universidade Federal do Ceará (UFC), na linha de pesquisa em Energia Renovável. Realiza pesquisas envolvendo os seguintes temas: energia eólica, energia solar, biomassa, biocombustíveis, economia do hidrogênio e planejamento energético; além de lecionar disciplinas técnicas no IFRN - Instituto Federal de Educação, Ciência e Tecnologia do Rio Grande do Norte.

\section{Lutero Carmo de Lima}

Graduou-se em Física pela Universidade de Santo Amaro, mestrado e doutorado em Engenharia Mecânica pela Universidade Federal de Santa Catarina e Universidade de São Paulo, respectivamente, e pós-doutorado na Universidade de Miami, no Clean Energy Research Institute. Atualmente ocupa o cargo de professor adjunto no Curso de Física da Universidade Estadual do Ceará, onde atua em nível de graduação e pós-graduação, trabalhando também com problemas fundamentais das ciências térmicas, instrumentação e energias alternativas. Publicou mais de uma centena de artigos em revistas e congressos nestes assuntos.

\section{T. Nejat Veziroglu}

Tem 47 anos de serviços dedicados ao Departamento de Engenharia Mecânica e Aeroespacial da Universidade de Miami, conduzindo esforços para desenvolver energias alternativas em substituição aos combustíveis fósseis. Há 36 anos fundou o CERI (Clean Energy Research Institute - Instituto de Pesquisa em Energia Limpa) sendo seu Diretor até a presente data. Presidente Fundador da Associação Internacional do Hidrogênio Energético (IAHE em Inglês) e é Editor da Revista International Journal of Hydrogen Energy (Fator de Impacto 3.9). Criador da Conferencia Hydrogen Economy Miami Energy (THEME), a primeira conferencia do mundo em energia do hidrogênio a qual organiza desde 1974. Também iniciou diversas conferencias em energia no Mundo incluindo a World Hydrogen Energy Conferences e a World Hydrogen Technologies Conventions. Publicou mais de 350 artigos e relatórios científicos, editou mais de 160 volumes de livros e anais e foi co-autor do livro Solar Hydrogen Energy: The Power to Save the Earth. Foi nomeado para o Premio Nobel de Economia no ano 2000, é membro de mais de 20 organizações profissionais e recebedor de diversos Doutorados Honoris Causa e prêmios prestigiosos à nível internacional. Foi selecionado para a Academia de Ciências da Argentina e recebeu o Premio da Presidencia da Turquia, a Medalha I.V. Kurchatov agraciada pelo Instituto Kurchatov de Energia Atômica da Russia e recebeu o Premio Energia para a Humanidade agraciado pela Sociedade Global de Energia. 